TEXTO CLÁSICO 



\title{
Halbwachs y Keynes: el doble espejo de las ciencias sociales ante la crisis de los años treinta
}

\section{Halbwachs and Keynes: the double mirror of the social sciences in the crisis of the 1930s}

\author{
Luis EnRiQue Alonso \\ Universidad Autónoma de Madrid
}

\author{
Ignacio DuQue \\ Instituto Nacional De Estadística
}

\begin{abstract}
El método sigue siendo conceptual, pero se aplica de forma diferente pues el teórico - sea o no consciente de ello-debe responder a las cuestiones que la realidad le plantea. Y tal vez sea la señal de que, hoy como ayer, el método no puede ser plenamente conceptual más que en apariencia. Pero lo que es más grave es que el teórico sea totalmente incapaz de identificar la parte de la realidad que se introduce subrepticiamente en sus concepciones. Además, la realidad no puede compartimentarse. Hay que considerarla en su totalidad o no considerarla.

Maurice Halbwachs (2016:97 [1940a, 41])

... je persiste à croire que l'économie mathématique est surtout intéressante à titre d'application des mathématiques, et pour les mathématiciens. Pour nous outres, c'est un roman, un beaux roman d'ailleurs. J'ai lu Cournot, j'ai lu Walras, j'ai lu Pareto, et je dois dire qu'ils ne m'ont pas appris grandchose sur la réalité même, sur les faits eux-mêmes. Je n'ai pas eu l'impression que cela pût être incorporé à la science positive proprement dite, et réelle

Maurice Halbwachs (1972: 406-7 [1937, 30]).
\end{abstract}

\section{INTRODUCCIÓN}

Presentamos aquí dos textos de Maurice Halbwachs traducidos por primera vez en español. El primero "Keynes et son école" apareció en 1940, como capítulo no independiente, en una pequeña compilación de textos de nuestro autor que tenía por título Sociologie économique et démographie publicado por la Editorial Hermann de París (Halbwachs, 1940b, 9-19) El segundo "La théorie 
général de John Maynard Keynes" se publicó en el mismo año de 1940 en Annales sociologiques (Halbwachs, 1940a: 25-41)1.

Sólo la impresión de ver juntos dos nombres de la altura de Halbwachs y Keynes (auténticos gigantes en las ciencias sociales del siglo XX) le dan a estos escritos un atractivo casi irresistible; pero son muchas las cosas que nos aportan estas dos piezas de Halbwachs sobre la principal obra de Keynes: en ellas se encuentran indagaciones fundamentales sobre la sociología económica a realizar desde las bases asentadas por el pensamiento de raíz durkheimiana, críticas a los modelos de razonamiento de la economía académica de su tiempo -incluso en sus versiones más heterodoxas de la época como era el keynesianismo naciente y su entorno- y en, suma, un reclamo latente y manifiesto a un enfoque radicalmente interdisciplinario que históricamente se ha predicado en incontables ocasiones, pero sólo en muy pocas veces (y Halbwachs es una de sus rotundas excepciones) se ha practicado hasta hoy mismo.

La enorme curiosidad intelectual y la cultura verdaderamente enciclopédica de Halbwachs le hacen descubrir pronto la aparición de una obra de auténtica relevancia histórica como la Teoría general del empleo, el interés y el dinero de Keynes y ya en 1938 (un par de años después de su aparición) había dado notica de su publicación, así como otros textos de la corriente teórica en la revista insignia del pensamiento durkheimiano en Francia ${ }^{2}$. A lo largo de su vida fueron literalmente cientos las obras de economistas, sociólogos, estadísticos e historiadores de primera línea mundial tanto anglosajones como alemanes e incluso italianos que fueron reseñados e incluso introducidos y difundidos en el ámbito intelectual francés por Halbwachs, y Keynes no fue la excepción. Esta primea nota se convirtió luego en los dos estudios de 1940 que aquí publicamos, siendo el segundo autor francés -después de Étienne Mantoux en 1937 y al que cita Halbwachs inmediatamente- que le otorga la atención que se merece la obra y presenta una reflexión en profundidad sobre un libro que iba a cambiar el

${ }^{1}$ Las traducciones que aquí presentamos las hemos extraído de la excelente edición que ha realizado Gilles Montigny de los textos de Maurice Halbwachs sobre Keynes y su escuela y que ha titulado como Keynes, abstraction et expérience. Sur la Théorie génerale (Halbwacs, 2016) El primer artículo que aquí presentamos se encuentra en las páginas 68-80 de este libro y el segundo en las páginas 81-97. El estudio introductorio, las notas críticas, el anexo y la bibliografía son de enorme interés y demuestran el enorme conocimiento del editor sobre la producción sociológica de Maurice Halbwachs, cosa que ya había anticipado en otra magnífica síntesis introductoria a la vida, obra y conceptos fundamentales del clásico francés, véase Montigny (2005). Ambos textos tienen mínimos "préstamos" entre ellos ([\{2016, 71-2\} \& \{2016, 87-8\}], [\{2016, 77\} \& \{2016, $90-1\}],[\{2016,78\} \&\{2016,91-2\}])$, que no les resta independencia y complementariedad de puntos de vista

${ }^{2}$ Montigny recoge en su compilación de Halbwachs (2016: 65-66 y 67) dos noticias en Annales sociologiques de la aparición tanto del libro de Keynes objeto de estas páginas (Halbwachs, 1938b) como del muy importante también, Essays in the Theory of Employement de la grandiosa economista británica Joan Robinson, que Halbwachs (1938d) lee lógicamente en clave keynesiana y que indican lo atento que estuvo a lo largo de toda su vida en el seguimiento de la producción de los grandes economistas internacionales. 
pensamiento económico del siglo, pero que en Francia todavía no había tenido ninguna repercusión notable.

Keynes parecía ya de entrada un personaje que le podía interesar a Halbwachs, ambos habían analizado el tema de la probabilidad, desde enfoques y tipos de textos diferentes, pero que indicaban afinidades intelectuales innegables, ambos también se habían interesado por una psicología económica que explicaba comportamientos poco racionales según la escuela clásica (los precios del suelo en Halbwachs, las conductas financieras en Keynes y sus "espíritus animales"); ambos, en suma, abordaban los comportamientos económicos, el ahorro, el consumo o la inversión, rompiendo la tradición del equilibrio automático y natural de los mercados. Sin embargo, es evidente que entre los enfoques de Keynes y los de Halbwachs se abrían interpretaciones prácticamente antagónicas y el autor francés encontraría en estas dos largas y enjundiosas recensiones que traducimos, espacio no sólo para elogiar, sintetizar y divulgar de primera mano ${ }^{3}$ el núcleo de la opera magna de Keynes; también hay una fuerte crítica metodológica donde le opone al método abstracto deductivo de la obra, la sociología positiva, o mejor la manera de trabajar con hechos sociales contrastados que se derivan de comportamientos poblacionales concretos -registrados en datos- y no de hipótesis genéricas y descontextualizadas sobre las bases del comportamiento económico humano universal. La psicología de Keynes y sus modelos de propensión al consumo o de preferencia por la liquidez eran radicalmente individualistas y abstractas, la psicología de Halbwachs reclamaba lo colectivo, las representaciones sociales y los modos de vida construidos como experiencias comunes.

Es evidente que Halbwachs opone a Keynes la batería conceptual casi completa de la sociología durkheimiana y muy directamente la obra del gran economista François Simiand, muy admirado y seguido por Halbwachs, considerado por él su maestro y amigo, integrante indiscutible de esta escuela, encargado ya en la revista fundacional del círculo, L’Année sociologique (1896-1913) de la sección "Sociologie économique" y que ya se había enfrentado a la teoría monetaria de Keynes. Muerto Simiand en 1935, sería el propio Halbwachs el que se encargaría de llevar en los Annales sociologiques -la revista heredera del proyecto durkheimiano original, una y otra vez renaciendo de sus cenizas, por fin refundada en 1934- la misma sección sobre sociología económica, donde aparecería el segundo texto que aquí publicamos y que testimonia la enorme importancia que en toda esa época de formación de la sociología francesa se da al encuentro intelectual entre la economía y la sociología.

${ }^{3}$ Se ha estudiado que la lectura y anotaciones que realiza Halbwachs es sobre la versión original en inglés y no sobre la traducción canónica francesa de la Teoría general de Keynes, que aunque disponible desde 1939, no vería la luz hasta 1942 y con muchas dificultades por ser considerada peligrosa y filocomunista por las autoridades colaboracionistas. Montigny (2016: 32-35) resalta que tanto la terminología y la notación de las ecuaciones, como las citas literales que toma Halbwachs del autor británico, además de no coincidir con la versión francesa de la época, son mucho más respetuosas con el original. El tema de la recepción del keynesianismo en Francia es objetivo de un apasionante estudio del siempre sólido Pierre Rosanvallon (1987). 
No entraremos ahora en las críticas al proyecto de sociología económica de los durkheimianos (por su positivismo, por su lejanía del conflicto y las prácticas políticas de los actores sociales, etc.), o en la, también reprochada por algunos, dependencia de Halbwachs en la manera de abordar estos temas con respecto a Simiand ${ }^{4}$, lo que si podemos decir -y de ahí el interés de la recuperación de los textos que nos ocupan-, la enorme entidad propia y originalidad de Halbwachs abordando estos temas, introduciendo dimensiones y conceptos que no están en Simiand y que, como veremos, le dan a su obra una coherencia especial. En estos trabajos de Halbwachs sobre Keynes se aportan claves muy sintéticas para la fundamentación de una sociología económica continental de raíz durkheimiana (la sociología económica anglosajona seguramente tiene en Karl Polanyi su principal referencia clásica) que habría sido literalmente imposible sin las monumentales investigaciones y los conceptos desarrollados por el propio Halbwachs y cuyo impulso se ha ido ampliando hasta llegar a la obra de Pierre Bourdieu y hoy mismo a Löic Wacquant o Serge Paugam.

Los dos textos traducidos aquí han tenido muy poca difusión, el hecho de anticiparse a la recepción "oficial" de Keynes en Francia, prácticamente ya en la segunda postguerra mundial y con el comienzo de la planificación indicativa francesa, que su autor encontrase más eco cuando ha sido redescubierto como sociólogo de la memoria colectiva -o incluso como sociólogo urbano- que como una voz competente para criticar a Keynes entre los economistas del ámbito francófono y que la fecha de aparición, 1940, supusiese ya encontrarse con la mordaza y el silencio intelectual impuestos por la ocupación, fueron causas todas ellas que contribuyeron a dejar sin impacto los trabajos que aquí recogemos. Pero el desconocimiento ha sido tal que en muchas de las bibliografías especializadas o en recuentos de la obra de Halbwachs ni siquiera aparecen reseñadas.

Recuperar estos escritos en español aquí y ahora, con el eterno debate de la pervivencia o no del keynesianismo como corriente económica con utilidad y capacidad vigente de acción en el presente entorno de postcrisis financiera, con amenazas y avisos permanentes de nuevas recesiones, con condiciones de vida tan descaradamente expuestas a los efectos perversos del ciclo económico que siempre es difícil saber si estamos superando una crisis o entrando en otra o con un marco económico mundial que no sabemos si se está globalizando o desglobalizando, creemos que tiene un interés intrínseco pues muchos son los que encuentran paralelismos entre nuestros días y el tiempo en que se redactaron estas páginas y muchos otros los que consideran necesario mantener viva la herencia keynesiana. Pero nosotros consideramos además la pertinencia de una publicación así para reforzar el avance de una sociología multidimensional que estudia la génesis de los comportamientos económicos en sus marcos sociales y en las potencialidades que todavía se encuentran en la obra de Halbwachs para ayudarnos a realizar esta tarea intelectual, obra que todavía está esperando traducción

${ }^{4}$ Para desarrollar este argumento, véase la importante obra que ha desarrollado Phillippe Steiner sobre el tema (Steiner, 2005), este mismo autor ha sido uno de los grandes animadores de la sociología económica europea contemporánea en su actual renacimiento (Steiner, 1999a). 
al español en lo que se refiere a sus aportaciones más directas relacionadas con la sociología económica, del consumo y las necesidades.

\section{SOBRE LA RECUPERACIÓN DE LA OBRA DE MAURICE HALBWACHS, UN PROYECTO QUE NO CESA}

La presencia editorial en el panorama sociológico internacional que ha tomado la obra de Maurice Halbwachs en estos últimos años está siendo realmente espectacular y ha significado además de una auténtica recuperación, una revalorización de su figura intelectual, estamos como dicen Marie Jaisson y Christian Baudelot, ante un sociólogo reencontrado ${ }^{5}$. De su conocida posición de discípulo de Émile Durkheim, con su perfil clásico de alumno del Liceo Henry IV de París -donde recibió clases del mismo Henry Bergson, luego presente polémicamente en sus escritos-, y más tarde estudiante en la imprescindible por entonces Escuela Normal Superior, cosa que lo sitúa entre los intelectuales típicos de la Tercera República francesa: defensores del laicismo, el racionalismo científico, el método positivo y la reforma social. Pero en el redescubrimiento de Halbwachs hemos conocido a algo más que un filósofo de la escuela positivista francesa, seguidor de Leibniz, hemos descubierto que nos hallamos ante un auténtico pionero en la formación de la sociología económica europea -en compañía, seguramente, con su amigo entrañable; el ya citado economista e historiador económico François Simiand-; de este modo al colaborador y continuador de la labor sociológica de Durkheim (desde 1901 en L'Année Sociologique y las revistas que siguieron en esta línea), hay que añadir al estadístico que impulsa diferentes asociaciones científicas francogermanas, y europeas en general, para la aplicación de esta disciplina a los estudios sociales; al introductor en Francia y difusor internacional de la obra de Weber, Pareto, Veblen, el propio Keynes o la primera Escuela de Chicago (universidad a la que viajó, con la que mantuvo contactos directos y de la que extrajo un buen número de saberes metodológicos ${ }^{6}$ ), pero sobre todo a un gran enriquecedor temático y metodológico de la práctica sociológica y la conciencia cívica de su tiempo ${ }^{7}$.

Animador máximo de la escena francesa de las ciencias sociales en los años veinte y treinta del siglo pasado, formalmente catedrático en la Universidad de

${ }^{5}$ Es el título de una de las más interesantes compilaciones sobre la recuperación de la obra de Halbwachs en sus diferentes dimensiones realizada por sociólogos franceses actuales de primera línea ver Jaisson y Baudelot (2007).

${ }^{6}$ Existe una magnífica edición actual de los textos de Halbwachs sobre Chicago y en general sobre los Estados Unidos. Desde su conocido y muy académico, "Chicago una experiencia étnica", escrito a la vuelta de su principal estancia en aquella universidad a principios de los años treinta, hasta sus artículos periodísticos sobre Estados Unidos se pueden encontrar hoy rescatados y presentados con un gran trabajo introductorio de Christian Topalov (Halbwachs, 2012)

${ }^{7}$ Afortunadamente disponemos de una casi monumental biografía de Maurice Halbwachs, que además de completa y bien documentada es apasionante por su cercanía al personaje, su escritura y su reflexión sobre la memoria y el olvido, véase Annette Becker (2003) 
Estrasburgo primero y de la Sorbona de París desde 1935, su relación con la historia económica -y la configuración de lo que será luego la Escuela de los Annales, cumbre de la historiografía francesa-, con la psicología social, con la estadística, con los estudios sociales de la realidad francesa de su época y hasta con el movimiento socialista francés de su tiempo en el que se comprometió y militó, lo hacen ser uno de los personajes más inquietos, polifacéticos y fecundo del panorama intelectual de entreguerras o mejor de la primera mitad del siglo XX. Su conocido y trágico final en el campo de concentración de Buchenwald en marzo de 1945, después de haber sido elegido el año anterior en el Collège de France para una cátedra que nunca pudo ocupar; perseguido y acosado por la Gestapo terminó sus días después de una auténtica tragedia familiar, debilitado, abandonado y desasistido de cuidados en su terrible cautiverio poco antes del cierre de la Segunda Guerra Mundial. Algo inmensamente trágico y paradójico a la vez se percibe en una muerte provocada por el ejército alemán, para alguien que se había implicado tanto y tanta ilusión había puesto en impulsar las relaciones de aproximación, cercanía y colaboración intelectual entre Francia y Alemania 8 .

Las diferentes facetas del pensamiento de Halbwachs están fuertemente interrelacionadas, su sociología económica de las clases sociales y el consumo -quizá la parte de su obra que más se acerca temáticamente a las revisiones realizadas por nuestro autor de la obra cumbre de Keynes que aquí presentamos- es interdependiente de sus trabajos sobre la morfología social, de sus aportaciones sobre la metodología de las ciencias sociales y de sus muy renovadoras y radicalmente novedosas obras sobre la memoria colectiva y, en general, sobre la psicología común de los grupos sociales. En los textos que recuperamos se aprecia claramente el enfoque multidimensional de Halbwachs, lo que parecen dos reseñas sobre la obra de Keynes nos remiten a problemas metodológicos centrales para el nacimiento y la pertinencia de una sociología económica como disciplina de pleno derecho -la crítica al enfoque abstracto, descontextualizado y sin referencias positivas a grupos sociales reales que domina en el genial economista británico- y a una profunda reflexión sobre las raíces sociales históricas, concretas y prácticas de comportamiento económico realmente existente.

${ }^{8}$ Es habitual referirse al trágico final de Halbwachs, citando los testimonios literalmente bellísimos, y tristísimos, de Jorge Semprún sobre la muerte del que fue su profesor y que vivió de manera muy próxima al estar internado en el mismo campo en varias de sus obras, por la importancia intrínseca de la obra puede destacarse La escritura o la vida (Semprún, 1995). Annete Becker en su biografía le dedica un capítulo final, donde no sólo a partir de otros testimonios personales de la época, sino también de un amplio material documental recabado en varios archivos especializados de medio mundo, reconstruye minuciosamente los últimos días de Halbwachs en Buchenwald; el tema nos lleva también a observar las diferencias entre el carácter literario de la evocación de los acontecimientos que hace Semprún y la reconstrucción genuinamente histórica que hace Becker, cosa que nos lleva al mismo centro de la obra de Halbwachs y los marcos sociales de la memoria. Pierre Bourdieu hizo también un impresionante homenaje/testimonio conectando la muerte Halbwachs con su práctica sociológica, a modo de lo que había hecho unos años antes otro gran intelectual: Georges Canguilhem, el importante texto de Bourdieu ya desde su título es sobrecogedor: "El asesinato de Halbwachs"(Bourdieu, 2008). 
Es evidente que las críticas que Halbwachs realiza a Keynes en los textos que aquí editamos sólo pueden entenderse cuando observamos el enfoque con el que afronta la conducta económica. Desde la tesis doctoral de 1912, La Classe ouvrière et les niveaux de vie, Halbwachs se posiciona no sobre el estudio del consumo en abstracto, o su propensión natural y global en función del precio y el nivel de renta individual -típico de las teorías marginalistas de la economía neoclásica-, sino por los modelos de consumo de las diferentes clases sociales, tomando como referencia central, la clase obrera ${ }^{9}$. No es en la producción, ni en la división del trabajo donde puede buscarse el origen de la conciencia de clase, sino en el escenario social de la vida obrera, y Halbwachs enfocado a la fábrica y la pura materialidad, el obrero se aísla en sus representaciones sociales y las relaciones humanas del trabajador se estrechan y concentran en su cultura interna, frente a otras clases donde su visión de la vida social y sus conexiones con el resto sociedad son mucho más amplios. Es por tanto en la comparación jerárquica que hacen los trabajadores con otras clases, sus géneros de vida diferenciados

${ }^{9}$ De manera muy original para su entorno académico, Halbwachs postula que es posible dar cuenta de esta jerarquía social a través del estudio de los niveles de vida y de los hábitos de consumo. Dicho de otro modo, no es tanto por el lado de la producción (como se han desarrollado habitualmente desde la teoría marxista) como del lado del consumo por donde se revela pertinente la investigación sobre la estratificación social en un sentido global. Es evidente que Halbwachs conocía bien la economía institucionalista clásica norteamericana en su disputa con el paradigma marginalista y siguiendo en eso las aportaciones de Veblen, Halbwachs está convencido de que la forma de consumo de un individuo está definida por la clase de pertenencia, mostrando, por ejemplo (quizás el ejemplo más conocido) que los obreros gastan menos, a iguales ingresos, en alojamiento que las demás clases (sobre todo los empleados). Los gastos en ropa y calzado, por el contrario, son comparativamente más importantes ya que son el testimonio a los ojos de los demás de la vida social del obrero, de la que está precisamente privado por su trabajo. Evidentemente Halbwachs leyó a Veblen, e incluso le dedicó un artículo en La Revue philosophique en 1921 y lo cita en su tesis de 1912 (Halbwachs, 1912, 410). Pero el autor francés le da mucha menos importancia que Veblen a la imagen que el individuo quiere dar a los demás al consumir. Su perspectiva se sitúa en el prolongamiento de las reflexiones de Durkheim sobre la jerarquía social y las representaciones que se desprenden de ella y, por ello, en Las clase obrera y los niveles de vida y en general a lo largo de su obra, parte no del ansia de demostración simbólica sino de la idea de que el obrero está en contacto con la materia (en un sentido casi total del término) y no con las ilusiones de los hombres: su trabajo se aleja del centro de la vida simbólica y considera lo material como algo relacional. Halbwachs propone una clasificación de gastos en función a la vez de su cuantía y periodicidad, y muestra que sus representaciones, en particular, las de los precios de los productos en cuestión, varían según esos dos criterios. Así es como para los productos alimenticios (de débil cuantía y de gasto frecuente) los obreros no "regatean": el precio les parece "natural". En la ropa, por lo contrario, (producto de mayor cuantía, pero de periodicidad menos frecuente, les falta un punto de referencia y prefieren elegir un artículo más barato, minimizando así el riesgo de pagarla de más. Halbwachs abrió así la vía a los estudios empíricos en los que se relacionan los hábitos de consumo y las representaciones compartidas por una misma clase social; introduce la noción de necesidad social, mostrando que la conciencia de clase socializa al individuo y por último, se refiere a las prácticas de su grupo en las compras poco frecuentes, es decir, las que deben ser programadas con tiempo, sin olvidar los cambios de estas necesidades a lo largo de los ciclos históricos de vida de los grupos sociales, todo ello le emparentaba directamente con un institucionalismo económico que lo distancia del formalismo aempírico de la economía anglosajona del que encuentra amplios residuos en la obra de Keynes. 
y sus estilos de consumo lo que les hacen desarrollar una psicología colectiva diferente y opuesta a otros grupos sociales ${ }^{10}$. Es fuera de la fábrica donde la clase obrera crea sus representaciones sociales, es en la esfera del consumo y en la construcción de los niveles y estilos de vida desde se forjan las distinciones y las comparaciones sociales. Frente a la economía deductivista, abstracta y descontextualizada que, según Halbwachs el propio Keynes plantea, la idea de consumo y el comportamiento de los agentes económicos no puede separarse, según el autor francés, de la jerarquía de las necesidades percibidas y las estructuras sociales que condicionan la actividad mercantil ${ }^{11}$.

De esta forma, la sociología económica de Halbwachs confiere un lugar fundamental a la integración y la participación social en la construcción de las prácticas económicas, desligándose tanto de la idea de la alienación o de la explotación en el proceso de trabajo como eje de la explicación social de las dinámicas sociales típico de la tradición marxista, como también del individualismo metodológico y del egoísmo racionalizador proveniente de la economía liberal. Esta dimensión de contextualización del consumo en las clases sociales y su jerarquía, se completa con la importancia que en la sociología de Halbwachs se

${ }^{10}$ Las clases sociales no pueden existir más que en sociedades estructuralmente jerarquizadas y esa jerarquía reproduce y a la vez es el producto, de una representación colectiva de la sociedad y de los lugares que los grupos que la componen ocupan en ella. Las diferencias de clase, se cristalizan siempre en la relación que mantienen los grupos sociales con los valores, con el ideal colectivo de sociedad. Halbwachs siempre consideró ese ideal como un foco donde se concentran todos los elementos de la vida social y desde el que se construye su sentido. Para nuestro autor la clase obrera es la que está más alejada de ese foco y cumplir con su trabajo la encierra en sus representaciones sociales particulares. Pero, por el contrario, cuanto más ascendemos por la jerarquía social, los grupos sociales están más inmersos en un conjunto de redes de socialización que tienden a darle la idea de universalidad y apertura. La conceptualización de Halbwachs de la construcción relacional de la vida económica, y por lo tanto, inseparable del juego de los grupos sociales en presencia en un espacio económico -frente a la presentación objetivista del precio como expresión de las cualidades intrínsecas de un producto-, se halla en muchas partes de su obra y en su libro póstumo La Mémoire collective nos lo podemos encontrar expresamente: "Mais, précisément, parce que les prix résultent d'opinions sociales en suspens dans la pensée du groupe et non des qualités physiques des objets, ce n'est pas l'espace occupé par les objets, ce sont les lieux où se forment ces opinions sur la valeur des choses et où se transmettent les souvenirs des prix, qui peuvent servir de support à la mémoire économique" (Halbwachs, 2001/1950: 98)

${ }^{11}$ La concepción de necesidad en Halbwachs pretende tender un puente entre subjetivismo y objetivismo. Se trata siempre, para él, de un "estado de conciencia" que tiene su origen en las representaciones colectivas, pero el término ha de ubicarse en un concepto más amplio: la discusión sobre la definición de las clases sociales. Bajo su punto de vista, la conciencia de clase, necesaria para hablar de clase social, se manifiesta a la vez en la memoria colectiva (diferenciada en la clase obrera de otras clases sociales) y en lo que George Gurvitch (1976: 348/2) llamaba una "psicología de las necesidades". Semejante concepción de la clase social es pues un doble punto de inflexión de la concepción marxista: en primer lugar, porque pone el énfasis más en el consumo que en la producción; en segundo lugar, porque apela a investigaciones empíricas. Pero también se aleja de cualquier concepción naturalista, el consumo de un individuo que demanda bienes para satisfacer una utilidad sin descripción sociológica de sus marcos de acción a la vez que reclama un estudio sistemático del número de trazos comunes que debidamente catalogados, pueden revelar la configuración de un grupo social. La posibilidad material de medir los gastos, gracias a los datos estadísticos, impregna también la noción de necesidad en Halbwachs y sus estudios socioeconómicos. 
le otorga a la institución familiar en los comportamientos económicos, tanto en su función de construir la lógica de las necesidades percibidas y sus prioridades, como en la importancia en la integración y socialización de los comportamientos individuales en marcos de referencia genuinamente sociales ${ }^{12}$.

${ }^{12}$ Así, según Halbwachs, la propia condición obrera está expresada en un marco social y familiar que lo aleja de cualquier versión del marxismo productivista sino también del individualismo metodológico típico del marginalismo neoclásico, apareciendo siempre instituciones sociales intermedias. Así al considerar que el consumo es en sí mismo un fin, y que el obrero trabaja para alimentarse, no que se alimenta para trabajar, considera que las comidas deben de considerarse desde un aspecto social y no sólo económico o directamente material, pues considera este proceso de alimentación para el obrero la ocasión y el medio esencial de entrar en la sociedad. Por ejemplo, la comida familiar va a ser el eje de la socialización. Estudiando atentamente los presupuestos familiares, Halbwachs se da cuenta de que, en los medios obreros, la parte de ingresos que se gasta en necesidades vitales es una expresión de su propia posición de clase y de su modo de incrustación en el juego de fuerzas sociales. Por tanto, la familia es la unidad consumidora por excelencia: se puede incluso decir que consumir es su función esencial, la única que se manifiesta fuera de su realidad. Porque no trabaja como familia (en nuestro sistema económico), incluso cuando todos sus miembros fueran a la fábrica. También, como jefe de familia, el obrero toma mejor conciencia de ser miembro de la sociedad. No obedece al instinto animal (el más arcaico) que lleva a la madre a asegurar la subsistencia de sus pequeños, sino que obedece a la necesidad social de asegurar a su familia (con la que él se confunde) y a conservar su lugar y rango dentro de la sociedad. No hay ninguna familia, según Halbawchs, sin un sentimiento de clase común a todos sus miembros. Un cierto nivel de consumo, el hábito de una alimentación a la vez tan regular y variada como sea posible en la que los alimentos de calidades diversas se encuentran en proporciones definidas, sirven mejor para mantener dentro del grupo doméstico el sentimiento de su situación social. Para estos aspectos de la sociología económica de Halbwachs como sociología del consumo véase el magnífico trabajo de Baudelot y Establet (1994). Afortunadamente en castellano nos hemos encontrado con recuperaciones y estudios de la obra de Halbwachs muy importantes en el terreno de la sociología de la memoria, la sociología de la religión e incluso en la sociología espacial, sin embargo, no se han publicado traducciones de sus grandes libros sobre la vida obrera, los niveles de vida, la evolución de las necesidades la metodología estadística o los trabajos poblacionales, vacío editorial que esperemos que se vaya cubriendo lo antes posible, incluso con textos como los que ahora rescatamos. En el terreno de los estudios nos encontramos con trabajos en español sobre este aspecto de la obra de Halbwachs: Arribas Macho (2008) ha revisado el Halbwachs estadístico; Carballo Rodríguez (2017) ha recuperado el muy interesante artículo "La estadística en Sociología" -publicado en 1944 (Halbwachs, 1944), aunque la intervención en el Centro Internacional de Síntesis se remonta a 1935-, con un interesante texto introductorio; Martínez Gutiérrez (2016) a raíz de su rescate de los famosos escritos de Halbwachs sobre la población de Estambul, al demógrafo que nos razona como es imposible separar del estudio de la dinámica demográfica de los marcos sociales y los géneros de vida -véase también Martínez Gutiérrez (2008a y 2008b). Roch (2008) nos han dejado estudios fundamentales sobre temas tan centrales en la obra académica y política de Halbwachs como los de la especulación urbana y la fijación de los precios de la vivienda (donde la formación de los precios poco tiene que ver, demuestra Halbwachs con equilibrios de mercado y mucho con poderes sociales y representaciones colectivas). Finalmente, Alonso e Ibáñez Rojo (2008) han analizado tanto la sociología del consumo y la necesidad en Halbwachs y sus contemporáneos de la Escuela Normal Superior (Edmond Goblot), como su influencia en la sociología del consumo en la obra de Chombart de Lawe, Baudrillard o Bourdieu. En general el número monográfico de la revista Anthropos sobre nuestro autor del que están extraídos estos últimos trabajos citados, sigue siendo una magnífica introducción a la multifacética obra de Halbwachs con cuidados artículos de especialistas franceses y españoles. 
Igualmente, estos planteamientos de la sociología económica de Halbwachs se fundamentan en su conocida visión de la morfología social (otra de las partes de su obra de raíz inequívocamente durkheimniana) y sus consecuencias para la metodología y la investigación social. En los textos que siguen a continuación se observa perfectamente el enfrentamiento de nuestro autor con la metodología y el modo de argumentación de Keynes -típica de toda la teoría económica formalista- y la defensa de una sociología positiva siempre levantada sobre observaciones directas de la estructura social y sus formas de configuración concretas. Como decimos la herencia durkheimiana aquí es omnipresente y omnipotente, pero eso no impide que haya desarrollos específicos en la visión de la morfología social en el discípulo que no sean netamente divergentes e incluso polémicas con respecto a las observaciones del maestro ${ }^{13}$. La obsesión de Durkheim de encontrar tendencias de estabilidad y regularidad que conformaban los hechos sociales como casi invariantes temporales, es matizada o incluso superada por Halbwachs gracias, seguramente, al conocimiento y uso de instrumentos estadísticos mucho más avanzados y a su aplicación a los procesos de variación, cambio y transformación social. De la misma manera, este enfoque mucho más complejo sobre la interacción entre las variables se corresponde con una visión mucho más compleja del comportamiento social -ya sea éste adquisitivo, religioso, urbano/ habitacional, etc.--, circunscribiendo su explicación a estilos de vida de grupos sociales -genres de vie- que están conformados por dimensiones múltiples e interrelacionadas y que producen resultados observables. Todo lo contrario de las apriorísticas y simplificadas relaciones automatizadas -leyes traspuestas de la física clásica- que establece la teoría económica deductivista sobre la demanda de productos o sobre la preferencia por la liquidez que el propio Keynes sigue incorporando como ejes de su arquitectura económica.

Lo mismo ocurre con el papel fundamental que Maurice Halbwachs le otorga a la psicología colectiva de los grupos sociales y, en particular, a las disposiciones psicológicas de cada clase específica. Ya el planteamiento mismo de los marcos sociales y los lugares de la memoria, socializa e historiza el comportamiento económico y lo aleja del individualismo y del antihistoricismo propio de la teoría económica marginalista de raíz anglosajona. No nos resistimos a citar aquí lo que consideramos casi un resumen del programa sociológico de Maurice Halbwachs, a este respecto, y que se encuentra en uno de los pocos textos que durante casi cincuenta años, desde el año 1950 hasta justo finales de ese siglo, era accesible al lector en nuestro país "Estos motivos generales: espíritu familiar,

${ }^{13}$ Dos autores españoles nos hacen ver la evolución de los usos de la morfología social dentro de la escuela durkeimiana, desde el mismo Durkheim a sus desarrollos posteriores y sobre todo a su revisión por parte de Halbwachs, así, tanto Emilio Martínez Gutiérrez (2008b y 2016), como Fernando Álvarez Uría (2017) nos entregan sendos estudios sobre el pensamiento sociológico de Halbwachs contextualizado en el seno tanto de sus posiciones morales (laicistas y prosocialistas) como en sus disputas científicas con el mismo Durkheim y su escuela (su referencia principal) como con otros intelectuales franceses de su época que se posicionaban fuera de este círculo pero de gran influencia en la Tercera República francesas, dos ejemplos de sociología de la sociología aplicados a la evolución de la obra de Halbwachs. 
ambición, ahorro, busca de bienes materiales, de distinciones, deseo de mejorar su condición, no se presentan en ningún sitio como tendencia o disposición aislada abstracta. Están en cada uno porque están en el grupo del cual se es miembro, y su forma, su intensidad resulta de las condiciones propias del grupo, de su estructura, de sus relaciones con los demás [...] Debemos fijar nuestra atención sobre los diversos grupos humanos, reconocer cuáles son las representaciones colectivas de estos conjuntos cuál es su fuerza y su extensión, cuales sus límites. Tendremos que observarlos también en sus relaciones, buscar si corresponden a fases diversas de una evolución de la cual las sociedades humanas en su actual estado nos presentarían, yuxtapuestas, fases sucesivas y qué previsiones, en cuanto al futuro cercano, pueden sacarse de la comparación. Seguiremos nuestro examen de los motivos bajo su forma colectiva en el marco de las clases sociales, clases diversas, el más amplio y el más natural de todos los que se imponen a los hombres que viven en sociedad, aunque más tarde, y para no desandar nada haya que volver a otras categorías, a otras formas de asociación"14

La práctica social siempre nos remite a una memoria que no puede entenderse, desde esta perspectiva como algo solamente íntimo y menos aisladamente, sino como un permanente reingreso mental en las representaciones colectivas de los grupos sociales. El recuerdo no es una simple evocación personal es un hecho social estructurado y mantenido por los grupos sociales en los que los individuos se incluyen y toman su sentido. Esta apelación a los marcos sociales y a los lugares de la memoria que forman el recuerdo activo de los individuos le da en Halbwachs al comportamiento humano un permanente carácter de reconstrucción desde un presente social (estructurado y grupal) de las prácticas formalmente subjetivas del comportamiento personal ${ }^{15}$. Todas las piezas del pensamiento de Halbwachs van encajando en una visión que sólo se puede conceptualizar como una negación de facto de cualquier individualismo formalista y en especial del individualismo formalista económico como el que a pesar de

${ }^{14}$ Esta cita nos sirve de homenaje al propio Halbwachs, pero también a su traductor aquí, el genial escritor y político republicano Max Aub, que como una de las actividades en su desgarrador exilio mexicano tradujo el libro Analyse des mobiles dominante qui orientent l'activité des individus dans la vie sociale (Halbwachs, 1937), como Las clases sociales para el Fondo de Cultura Económico de México (Halbwachs, 1950), durante muchísimos años fue el único libro más o menos encontrable de Maurice Halwachs, en las librerías españolas, las traducciones históricas de sus libros y artículos de los años veinte, treinta en España y hasta primeros cuarenta (en México) habían quedado descatalogadas y desaparecido totalmente hasta que a finales de los años noventa y luego ya en los últimos años en los que hemos conocido felizmente la publicación en nuestro idioma de varios de sus libros fundamentales y muchos de sus artículos, así como múltiples análisis de gran calidad realizados por autores y autoras españolas. Así gracias a esta traducción de Aub y sus múltiples reediciones del Fondo, Halbwachs se convirtió en esos años en una referencia en todos los programas de estratificación social de las Facultades de sociología españolas y casi en el único testigo de la existencia de este autor francés entre nosotros. La cita está tomada de la tercera edición en español de 1964, ver (Halbwachs, 1964: 36-37) Es muy interesante la reflexión que hace José Antonio González Alcantud (2009: 81-94) sobre la tardía recepción de Halbwachs en España y los problemas de construcción de un relato histórico nacional que ponga en juego los marcos interpretativos de la memoria social.

${ }^{15}$ Como dice Ramón Ramos en su presentación a la edición en español 
sus múltiples valores positivos encuentra Halbwachs detrás de a principal obra de John Maynard Keynes.

Es esta coherencia de toda la obra de Halbwachs, sin la que no pueden entenderse los escritos aquí recuperados la que queríamos resaltar en esta presentación. Por otra parte, esta obra en su conjunto cada vez es más conocida y la relevancia que ha adquirido la obra de Halbwachs ha sido afortunadamente extraordinaria, no sólo se le ha redescubierto e incluido entre los fundadores continentales de una sociología económica europea que sigue produciendo obras de máxima importancia para el análisis de los procesos completos y complejos de consumo, urbanización, configuración de las necesidades, cambios en la estratificación social y un largo etcétera. También grandes sociólogos franceses han reivindicado y se han reivindicado en la tradición de análisis, en el estilo metodológico y hasta en la posición ética de Maurice Halbwachs; incluso el mundo sociológico anglosajón ha estado también atento a esta recuperación, dedicándole su atención grandes historiadores del pensamiento social que han acabado señalándolo como uno de los grandes clásicos mayores de nuestra disciplina ${ }^{16}$. Sin embargo, esta recuperación general no ha estado exenta de polémicas, lecturas diversas, valoraciones diferenciadas y matizaciones considerables y, en algunos casos, sorprendentes, que se relacionan con los escritos que aquí editamos A ello dedicaremos las páginas que siguen.

\section{SOCIOLOGÍA ECONÓMICA Y ANÁLISIS ESTADÍSTICO EN HALBWACHS: EL PUNTO DE VISTA DEL MÉTODO.}

Una vez comentado el contexto de la trayectoria intelectual y del proceso de recuperación de la obra de Halbwachs, resulta conveniente trazar el panorama general en que se sitúa su recepción y comentario de The General Theory. Dentro de la amplísima producción intelectual de Halbwachs la respuesta del texto de Keynes se sitúa en una encrucijada de dos grandes ejes. Temáticamente el eje su interés por la sociología económica y el análisis estadístico. Adicionalmente su texto se inscribe en el cruce con otro gran eje: el debate epistemológico sobre la metodología de aproximación a la realidad en las ciencias sociales, lo que Halbwachs mismo reclamaba como método positivo, en tanto que marca colectiva de la escuela durkheimiana. El enfoque esencialmente metodológico de la

16 Véanse, por ejemplo, las presentaciones que hacen grandes intelectuales anglosajones como la antropóloga Mary Douglas (1980) o el clásico sociólogo Lewis Coser (1992). Ambos textos, que le dan un papel central a Halbwachs en la historia de las ciencias sociales, indican el reconocimiento tardío, pero efectivo y profundo de la obra de Halbwachs en la producción de conocimiento social en lengua inglesa. En los diccionarios de sociólogos clásicos tan frecuentes en el panorama editorial inglés ya se incluye habitualmente a Maurice Halbwachs como uno de los grandes autores de la historia del pensamiento social, véase por ejemplo el clarificador artículo de Johs Hellbrekke (2007) en la compilación organizada por el historiador de la teoría social John Scott, quizás la más difundida en ese contexto intelectual . 
recepción crítica de la obra de Keynes por Halbwachs nos fuerza a realizar este tipo de contextualización.

Dos pinceladas sobre el contexto temático. Todas las esquematizaciones son problemáticas y alimentan el inacabado debate sobre la unicidad o multiplicidad de cualquier trayectoria intelectual, pero estas cesuras interpretativas son más difíciles cuando se trata de personalidades complejas y multifacéticas, como es la de Maurice Halbwachs. En todo caso, la temática de sociología económica y el análisis de los fenómenos sociales basado en fuentes estadísticas convencionales abarcan un amplio espacio en la producción de Halbwachs. En lo que se refiere a publicaciones materializadas en vida del autor van desde su tesis sobre los precios de las expropiaciones de París de $1909^{17}$ hasta sus publicaciones sobre Sociología económica y demografía en 1940 (Halbwachs, 1940c) y sobre la población de Estambul en $1943^{18}$, ya al borde de su trágico final en Buchenwald en marzo de 1945. En esta temática, se encuadrarían diversas obras mayores, tales como sus análisis de las condiciones de vida obrera de 1912 y $1933^{19}$, su revisión de la interpretación de su maestro Durkheim sobre las causas sociales del suicidio en $1930^{20}$, su contribución a la obra colectiva de L'Encyclopédie Française en $1936^{21}$, su Morfología Social de $1938 \mathrm{c}^{22}$ y, como ocurre siempre con Halbwachs, un enorme número de artículos, recensiones y otros textos no por breves menos sustanciosos.

Tienen relación con su temática estadística los textos sobre Quetelet y la teoría del Hombre Medio ${ }^{23}$ y el texto divulgativo con Frechet sobre el cálculo de probabilidades ${ }^{24}$, con un carácter más de tipo teórico y metodológico. Quedan fuera de estos dos ejes mencionados toda su obra, en parte anteriormente considerada, referida a los marcos sociales de la memoria, la psicología colectiva, la pedagogía, el análisis de las religiones y otros temas sólo al alcance de una curiosidad intelectual con tan pocos límites como los que exhibía Halbwachs.

Como se ha podido apreciar en el anterior apartado la mayoría de los procesos de recuperación de Halbwachs durante las últimas décadas han partido del

17 Les Expropriations et les prix des terrains à Paris (1860-1900) (Halbwachs, 1909), asunto luego retomado en su publicación La population et les tracés de voies á Paris depuis un siècle (Halbwachs, 1928).

${ }_{18}$ Sociologie Économique et Démographie (Halbwachs, 1940c) y La population d'Istanbul (Constantinople) depuis un siècle (Halbwachs, 1943)

${ }^{19}$ La classe ouvrière et les niveaux de vie. Recherches sur la hiérarchie des besoins dans les sociétés industrielles contemporaines (Halbwachs, 1912) y L'évolution des besoins dans les classes ouvrières (Halbwachs, 1933a). La publicación póstuma de sus dos textos sobre clases sociales (Halbwachs, 1955 y Halbwachs, 2008a [1937]), supone una revisión madurada de los trabajos anteriores, despojados de cualquier investigación empírica.

20 Les causes du suicide (Halbwachs, 1930).

${ }^{21}$ Le point de vue du nombre (HALBWACHS, Maurice SAUVY, Alfred; ULMER, Henri; BOURNIER, Georges, 1936).

${ }_{22}$ Morphologie sociale (Halbwachs, 1938c) 1913).

${ }^{23}$ La théorie de l'homme moyen. Essai sur Quetelet et la Statistique Morale (Halbwachs,

${ }^{24}$ Le Calcul des probabilités à la portée de tous (Fréchet y Halbwachs, 1924). 
redescubrimiento en su obra de diversos campos de investigación novedosos para su tiempo (la memoria colectiva, el consumo, las formas de vida, el urbanismo, etc.). No es fácil recontar los innumerables investigadores de muchas disciplinas que han resultado fascinados por los textos de un pionero en tantos campos y maneras de abordar el análisis social. Sin embargo, son menos los analistas que se han detenido a escudriñar el contexto metodológico en el que Halbwachs abordaba sus novedosos enfoques, esto es, al cómo y no solamente el qué de su ambiciosa producción. Como las recensiones de Halbwachs sobre Keynes van a hacer referencia a estos aspectos epistemológicos y de método, detallaremos a los autores que han aportado perspectivas de interés sobre la metodología de investigación de Halbwachs.

El ya citado aquí Giles Montigny, en su interesante introducción a la republicación francesa de las comptes rendues sobre Keynes, ya ha señalado algunos de los aspectos metodológicos por los que Halbwachs se aproximaba o rechazaba las elaboraciones económicas neoclásicas en general y las de Keynes en particular. Montigny $(2016,24-25)$ señala que las investigaciones empíricas de Halbwachs habían puesto el énfasis sobre la falta de concordancia entre la teoría económica clásica con la realidad concreta de la vida económica en el caso de sus dos tesis doctorales. En su tesis sobre el análisis de los precios del suelo de las expropiaciones de París había mostrado cómo el aumento de la oferta de suelo urbano puede acompañarse de un crecimiento de los precios, en contradicción con el modelo económico estándar. En su tesis sobre el análisis del consumo y la jerarquía de las necesidades de la clase obrera alemana a partir de encuestas, Montigny señala cómo sus comportamientos no sintonizan con los presupuestos apriorísticos de la utilidad marginal.

Desde una particular perspectiva, al tiempo empática y crítica, Michel Verret (1972) es quizá el primero que se adentra en la revisión metodológica de algunos de los campos en los que Halbwachs había innovado tanto, y lo hace con un texto denso pero vigente, a pesar de las casi cuatro décadas transcurridas. Metodología estadística, materialismo morfológico, sociología del consumo y análisis de clases (y de la posición de la clase obrera) son los cuatro aspectos metodológicos revisados por Michel Verret.

Verret (1972, 313-5) describe bajo el rótulo de "el buen uso de la cantidad" el empleo que hace Halbwachs del análisis estadístico y su fina percepción de la matematización pertinente de la realidad social. Una aproximación metodológica que luego en las recensiones de Keynes serán simplemente ligeros apuntes críticos sobre la economía neoclásica, desde una perspectiva conceptualmente avanzada por su temprana asimilación de las implicaciones epistemológicas del cálculo de probabilidades. En una ácida caracterización, asunto poco frecuente en una personalidad tan autocontrolada como la de Halbwachs, llama la atención sobre las bellas novelas de la economía matemática $a^{25}$. Verret señala que "au ro-

25 ««Aux beaux romans»(3) de l'économie mathématique, comme aux illusions du graphisme démographique ou aux naïvetés de la statistique administrative, Halbwachs oppose avec entêtement la question préalable des conditions de sens sociologique du modèle, de la figuration ou 
man psycométaphysique de l'économie politique bourgeoise, Halbwachs oppose les principes théoriques d'une analyse sociologique des besoins" $(1972,321)$ y de esta forma sitúa uno de los focos críticos con los que Halbwachs enfila en 1940 la recensión de The General Theory. ${ }^{26}$

Verret realiza una revisión metodológica crítica sobre el análisis de la estructura de clases en Halbwachs, y en particular a la posición de la clase obrera en la misma, aunque este aspecto tiene una relación solo tangencial con las compte rendues. La originalidad del análisis de Halbwachs sobre las clases sociales es, como señala Verret, notable y sus argumentos esenciales atraviesan todas sus obras. En tanto que grupos discontinuos de totalización de prácticas sociales y de consumo, su análisis se abrirá a la investigación empírica de la jerarquía de necesidades y también a la consideración de los aspectos ideológicos y de construcción grupal de los modelos dominantes.

En todo caso, Verret afronta de forma directa el más evidente punto ciego de la construcción halbwachsiana: su visión sobre las raíces de la alienación obrera, su posición sobre los trabajadores en la jerarquía social y el carácter atrapado de su situación en el proceso de producción de mercancías y de desarrollo social. Según Halbwachs lo constitutivo de la posición de los obreros en la sociedad es la relación de los mismos con la materia, su abandono de la vida social durante la producción y su falta de imbricación en las tareas intelectuales y de dirección, con independencia de las relaciones de propiedad de los medios productivos o de las relaciones técnicas al interior del proceso de trabajo. Verret señala los evidentes rasgos de etnocentrismo de clase y el carácter circular del análisis de Halbwachs, que define como patrones más excelsos aquellos que caracterizan precisamente la labor intelectual y relacional de la clase dirigente, para encontrar que finalmente el obrero se encuentra descrito como su negativo des-socializado.

la corrélation, et des conditions de validité, c'est-à-dire en définitive d'objectivité, de l'abstraction, si aisément tentée de confondre ses propres distinctions de pensée avec les distinctions réelles, ses classements avec les classes» (Verret, 1972, 215). El texto a que reenvía la nota (3) de Vernet es el siguiente: «Classes sociales et morphologie, Le point de vue du sociologue, op. cit.» y se refiere al texto incluido en la recopilación de Victor Karady de las conferencias pronunciadas en el Centre Polytechnicien d'études économiques y publicadas en 1937 (Halbwachs, 1972 [1937]). El texto aludido de Halbwachs es el que figura en una de las citas que encabeza nuestros comentarios. Este aspecto será justamente enfatizado posteriormente por Olivier Martin (1999), José María Arribas (2008), así como en los trabajos de Marie Jaisson y Eric Brian más adelante citados.

${ }^{26}$ El texto de Keynes rebosa referencias a leyes psicológicas ayunas de datos empíricos: valgan los siguientes ejemplos como muestra de una larga relación: "Thus we can sometimes regard our ultimate independent variables as consisting of (1) the three fundamental psychological factors, namely the psychological propensity to consume, the psychological attitude to liquidity and the psychological expectation of future yield from capital assets, (2) the wage-unit...and (3) the quantity of money...”(Keynes, 1973 [1936], 246-7); “... since these facts of experience do not follow of logical necessity, one must suppose that the environment and the psychological propensities of the modern world must be of such a character as to produce these results. It is, therefore, useful to consider what hypothetical psychological propensities would lead to a stable system; and, then, whether these propensities can be plausible ascribed, on our general knowledge of contemporary human nature, to the world in which we live"(Keynes, 1973 [1936], 250) 
Pero el análisis de Verret intenta además aclarar cuáles son los aspectos de su construcción teórica que contribuyen a estos puntos ciegos y propone como explicación lo que caracteriza como un idealismo durkheimiano que excluye del análisis sociológico las condiciones materiales del proceso de trabajo. En consecuencia, Verret apunta como explicación los límites de su materialismo morfológico, que analíticamente se detiene a las puertas de la fábrica, que conceptualmente se construye sobre la denegación de las aportaciones de los diversos marxismos y que inscribe su perspectiva y posición al interior del particular contexto de las luchas sociales en la Francia de entreguerras. Más adelante Michel Amiot (1991) realizará una segunda revisión de las críticas de Verret y de Georges Friedman, postulando una revisión crítica del concepto de materia (y espíritu) en Halbwachs.

Como contrapartida positiva Verret señala la importancia de los análisis de sociología del consumo de Halbwachs como crítica a los presupuestos ideológicos de la economía marginalista (supuesta interiorización del mercado en cada consumidor, reducción de todo interés al puramente económico) y postula una teoría del valor basado en la utilidad y la opinión sobre la utilidad (Verret, 1972, 321). Por lo tanto, el análisis sociológico del consumo lo es de las diferentes necesidades, de sus satisfacciones y equivalencias simbólicas a través de las diferentes posiciones de clase (Verret, 1972, 322).

En las antípodas de esta revisión metodológica de Halbwachs se sitúa Philippe Steiner (1999b), un cuarto de siglo después de Verret, y que comienza advirtiendo que no comparte el general entusiasmo del contexto francés de recuperación de Halbwachs (Baudelot, Establet, Pfefferkorn ${ }^{27}$, etc.). Según Steiner, Halbwachs no innova metodológicamente en su crítica a la economía clásica, sino que aparece "estancado" (Steiner, 1999b, 146-7) y se limita a reiterar los argumentos de Simiand. Más bien parece desconcertado y sin interpretación ante la "hegemonía" del pensamiento neoclásico, sin ir más allá del argumento durkheimiano de que la deriva formalista y matematizada de la economía tiene su causa en el cambio en el perfil profesional de los interesados por la economía, cada vez más dominado por matemáticos, físicos e ingenieros.

Philippe Steiner construye su interpretación sobre la constatación de varias paradojas. La primera es que por una parte Halbwachs otorga a Keynes, Robinson o Pigou un papel como ningún durkheimiano había hecho. Halbwachs reconoce el extraordinario interés que representa que el texto de Keynes esté

${ }^{27}$ Se puede matizar esta afirmación de Steiner sobre el entusiasmo de Roland Pfefferkorn, pues en uno de los más brillantes análisis sobre las relaciones de Halbwachs con la economía política realiza críticas bien claras a los planteamientos de Halbwachs frente a Keynes , pues ve en el autor británico una auténtica voluntad de intervención en el debate económico y social contemporáneo para solucionar los problemas de desempleo y estancamiento, y sin embargo en Halbwachs no encuentra Pfefferkorn el más mínimo asomo de ir más allá de la voluntad de realizar estudios descripticos de sociología económica sin ninguna intervención en el ámbito real de las decisiones y las políticas públicas, de la misma manera considera su incapacidad para estudiar el origen productivo de las riqueza y realizar su análisis en términos de distribución y consumo (Pfefferkorn, 1997: 31-46). 
focalizado en el problema práctico del empleo (aunque atribuye esta novedad a que el salario del obrero ya no es simplemente de subsistencia), pero se limita a repetir los argumentos de Simiand sobre que las categorías de Keynes son simples posibilidades sin ninguna base empírica (Steiner, 1999b, 149).

La segunda paradoja es que por esta denegación metodológica, o quizá también por falta de distancia temporal, Halbwachs no llega a captar los relevantes puntos de coincidencia entre el pensamiento de Keynes y la sociología económica durkheimiana, entre los que menciona Steiner: el razonamiento en términos de agregados monetarios, la importancia concedida a las opiniones, anticipaciones o representación de los agentes y el papel concedido al contexto social para comprender el funcionamiento del mercado, especialmente en el caso de los especuladores.

La tercera paradoja es, de acuerdo con la interpretación de Steiner, que a pesar de que Halbwachs no innova y no percibe las innovaciones de Keynes, su profunda asimilación de Weber y Pareto le hace desarrollar una novedosa aproximación a la relación entre motivos individuales, comportamientos socioeconómicos y la acción de los grupos sociales, en el mercado y fuera de él, lo que le aleja de la estricta ortodoxia durkheimiana, como se muestra en su revisión de El Suicidio en 1930. Tanto Halbwachs como Simiand intentan nutrir de carne, según Steiner, a las relaciones de causalidad situadas entre diversas magnitudes económicas, pero es Halbwachs el que da a esta aproximación su profundidad analítica, en razón de su interés por la psicología y la sociología del conocimiento y en razón de su indagación prolongada sobre el papel de los motivos de la acción (Steiner, 1999b, 153). La noción de motivo tiene un papel de causa social para la explicación del comportamiento individual y estos motivos se pueden relacionar con una estructura axiológica a la que las clases están más o menos cercanas, o tienen como atributos. Los motivos como la ambición, el ahorro, etc. están en cada uno porque están en el grupo del que se es miembro, con la intensidad y forma resultante de las condiciones del grupo, de su estructura y de sus relaciones con otros, y es al grupo al que los motivos deben ser adjudicados (Steiner, 1999b, 154-5).

Steiner ve los trabajos de Halbwachs como una tarea inacabada para el desarrollo de una sociología del conocimiento económico, apoyándose en Weber y Pareto y a partir de pistas de Simiand y con un anclaje en una aproximación cuantitativa de lo social.

Christian Topalov publica coetáneamente a Steiner dos relevantes revisiones metodológicas sobre las tesis de Halbwachs en Derecho (Les Expropriations et les prix des terrains à Paris (1860-1900), 1909) ${ }^{28}$, y Letras (La classe ouvrière et les niveaux de vie. Recherches sur la hiérarchie des besoins dans les sociétés industrielles contemporaines, 1912) ${ }^{29}$. Esta revisión ilustra la metodología de trabajo de Halbwachs en su investigación social y amplía lo trazado por los anteriores autores.

\footnotetext{
28 Topalov, 1997.

29 Topalov, 1999.
} 
Topalov enmarca magistralmente el contexto intelectual e institucional en el que se desenvuelve la estrategia del grupo durkheimiano entre los años 19031913, así como el trabajo desarrollado por Halbwachs para ampliar el ámbito de trabajo a la sociología económica, conseguir una mayor penetración social e institucional de su escuela y perfilar su propio itinerario vital y profesional. Topalov señala como objetivo de su revisión crítica considerar ambas investigaciones como un producto intelectual que se enfrenta al desafío de investigar dos ámbitos reservados a los economistas: la especulación urbana y los precios de la vivienda por una parte y las estrategias de decisión de unos consumidores específicos, los obreros, y su ajuste a las teorías de utilidad marginal con que la economía clásica caracterizaba el comportamiento del homo oeconomicus. Topalov va a intentar diseccionar el funcionamiento práctico de la metodología de análisis positivo con la que los discípulos de Durkheim pretenden el análisis científico de los hechos sociales, en ausencia de presupuestos teóricos "deductivos". De esta forma entra en el corazón de los argumentos que más adelante Halbwachs usará contra Keynes.

Lo esencial del método de Durkheim, como es bien conocido, se fundamenta en la sustitución de la imposible experimentación en ciencias sociales por la denominada experimentación indirecta, método comparativo o variaciones concomitantes. A través de lo que Topalov (1999, 20-22) denomina como "experimentos sociológicos", Halbwachs va a desarrollar sus análisis empíricos a partir de dos materiales originales: expropiaciones y precios ofrecidos por la estadística administrativa y presupuestos de gastos de familias obreras elaborados por la Oficina Estadística Imperial alemana y por el Sindicato de metalúrgicos del mismo país). Estos trabajos deberían permitir a Halbwachs explicar los hechos sociales por otros del mismo género y extraer conclusiones diferentes de los historiadores o economistas dominantes en su tiempo, marcando diferencias en cuanto a las pruebas de causalidad y los argumentos usados en su demostración.

Topalov (1999, 25-26) plantea que en el caso de las Expropiaciones el objetivo "antihistoricista" de Halbwachs es demostrar la llamativa tesis de que la ciudad tiene sus leyes propias (endógenas) ${ }^{30}$ y que el problema morfológico de las expropiaciones, el trazado de vías y las alzas de precio asociadas, tiene una causa igualmente morfológica: el crecimiento de la población y las necesidades de movilidad dentro de la ciudad. Comparando dos momentos del plano de París, 1855 y 1908, Halbwachs establece una tipología de las intervenciones y discute pormenorizadamente la razón de la apertura de cada uno de los tramos viarios. La conclusión es que la causa de tales intervenciones radica en las necesidades urbanas globales de desplazamiento y que estas fuerzas marcan la dinámica territorial y no las voluntades de los individuos en el mercado inmobiliario. Topalov

30 "Il y a donc quelque paradoxe que le Halbwachs des Expropriations ait pu être adopté comme père fondateur par des auteurs préoccupés de la morphologie des villes considérée comme disposition d'objets dans l'espace» (Topalov, 1999, 33). Juicio que reitera ("dissuader quiconque de croire que ce grand ancêtre est notre contemporain") a propósito del análisis de Halbwachs sobre el trabajo obrero, todo él deducido de otros autores y sin ninguna investigación empírica (Topalov, 1999,38). 
denomina a estos métodos de Halbwachs "recortar [o despiezar] los hechos por el pensamiento" (1999, 23-26) y "borrado [de la especificidad] del tiempo histórico" (1999, 27-30), con una clara eliminación de los fenómenos de sucesión y contigüidad, que son luego reintroducidos por el analista.

En el caso de la Clase Obrera y sus comportamientos de consumo el objetivo de Halbwachs es la falsación de las leyes de Engel, y el desafío es analizar el comportamiento de grupos discretos en relación con la distribución de variables en tablas de doble entrada por niveles de ingreso, tamaño de la familia, profesión, lugar de residencia y otras variables. Para navegar en un complejo y contradictorio mar de datos la estrategia de Halbwachs es diferente, y busca en primer lugar crear una diferenciación de los grupos sociales a partir de la discontinuidad observada en torno a valores agrupados (submodales), tratando de conseguir que los valores de cada subgrupo no se alejen mucho de la media.

Topalov $(1999,34-37)$ dedica bastante atención a lo que señala como tercer escalón metodológico en Halbwachs: el borrado de la singularidad, o eliminación de la investigación de aquellos casos que muestran medidas disonantes con las medias del grupo, evocando la autoridad de los trabajos de Bowley y también de Lexis. Topalov $(1999,36)$ señala que en el caso de las Expropiaciones este último procedimiento de borrado de singularidades se realiza invocando unas condiciones sociales que permiten explicar casi todos los efectos de apertura de vías, y en ocasiones sus contrarios.

No sorprenderá que el detallado trabajo de Topalov documente (1999, 3742) que entre las autoridades citadas en su estudio de la condición obrera (ausente de toda referencia empírica) se encuentran, salvo referencias muy generales de clásicos más o menos indiscutidos, el núcleo central de autores más estudiados por la densa red de discípulos de Durkheim, abundantemente referenciados en el Année Sociologique.

Topalov termina recalando en un asunto que Verret ya abordó críticamente: la caracterización de la clase obrera por Halbwachs, como alejada de la vida social por su tipo de trabajo. En las Expropiaciones añade Halbwachs un razonamiento particularmente lacerante, ya que atribuye la escasa dinámica inmobiliaria en los barrios obreros al insuficiente aprecio del alojamiento en la jerarquía de las necesidades obreras, rechazando que la causa sean los insuficientes ingresos de los obreros (Topalov, 1999, 42-44), asunto que remachará en su tesis de 1912 al enfatizar que la familia obrera no ha tomado conciencia de la importancia del alojamiento, con lo que claramente se perciben los límites de clase del socialismo normaliano francés y los intereses analíticos de su construcción erudita.

Unos últimos apuntes sobre las consideraciones de Topalov y el uso de la estadística por Halbwachs. Topalov señala, en su interesante reconstrucción del complejo "experimento" de las estadísticas de expropiaciones y construcciones, que Halbwachs busca construir "conjuntos-tipo" en los que queda borrada la contigüidad temporal y espacial, a la busca de una ley (more físico-natural) que muestre para las mismas causas siempre los mismos efectos. Topalov finaliza haciendo notar la impermeabilidad francesa a los desarrollos anglosajones de aplicación matemático-estadística al análisis económico y social, y considera 
como clave la insuficiente formación matemática de Simiand y Halbwachs, aunque señala que en otros casos en los que no se podía presuponer esta falta de formación, tampoco se produjo la permeabilidad ${ }^{31}$. Da la impresión que sobra algún argumento, pero sobre todo estos razonamientos tan personalizados resultan disonantes con los objetivos que la excelente reconstrucción de Topalov se había marcado: tratar a los textos históricos como objetos en su serie histórica (Topalov, 1999, 13) y poner el acento en los modos de establecimiento de los hechos y la retórica de la prueba (Topalov, 1999, 14).

\section{LA GRAN REVALORIZACIÓN ESTADÍSTICA DE MAURICE HALBWACHS}

Las anteriores consideraciones nos dan la pauta para introducir otra gran revisión metodológica de los trabajos de Halbwachs, realizada precisamente sobre sus trabajos más estadísticos. A tal efecto tomaremos como punto de partida los estudios críticos realizados bajo la dirección de Eric Brian y Marie Jaisson para la reedición por parte del INED ${ }^{32}$ de la publicación de 1936 Le point de vue du nombre, dentro del Tomo VII del proyecto colectivo de la L'Encyclopédie Française $d u X X^{e}$ siècle (editada a partir de 1935 y hasta los años 60 del siglo $\mathrm{XX}$ ). Se trata de una reconstrucción crítica monumental, con un gran número de enfoques y aspectos tratados que no procede detallar aqu $\hat{~}^{33}$, pero con un enorme esfuerzo de conceptualización de la metodología de trabajo de Halbwachs en el contexto largo de la evolución de la estadística, la sociología, la matemática, la antropología y la psicología francesas. Una revisión que ya había hecho a fondo Alain Desrosières (1985), señalando el papel clave de Halbwachs en el desarrollo de la estadística en la Francia anterior a $1940^{34}$.

31 "Si Wesley C. Mitchel reste ignore en France, Simiand connaît en revanche les travaux de Galton et Pearson, notamment parce qu'il travaillait à son étude des prix du charbon. Mais, comme toujours, les emprunts s'accompagnent de tris et de transformations. Cela tient aux ressources des emprunteurs : ni Halbwachs, malgré sa lecture approfondie de Quetelet, ni Simiand ne savent suffisamment de mathématiques pour comprendre Pearson. Mais les mathématiques peuvent s'apprendre et l'on peut observer au même rejet de la corrélation chez Lucien March dont la conversion au nominalisme pearsonien ne sera accomplie qu'en 1912. Sans doute les techniques de la corrélation restent-elles invisibles aux durkheimiens du fait de ce qu'ils cherchent : observer les relations causales au sein d'ensembles concrets qui seuls, à leurs yeux, peuvent les rendre intelligibles » (Topalov, 1999, 29-30).

${ }^{32}$ (Halbwachs, Sauvy, Ulmer, Bournier, 1936 [2005]).

33 Sin duda el aspecto más impactante, y atípico, es el capítulo dedicado a la recepción de la demografía de Halbwachs bajo el IIIer Reich (Gierl y Brian, 2005, 131-148) y la reconstrucción sobre los análisis y experimentos estadísticos que se hicieron en las SS sobre la proporción del sexo de los nacidos usando como fuentes los ficheros del propio personal de las SS (Brian, 2005b, 149-168).

${ }^{34}$ Y que de paso nos añade noticias preciosas del papel de los matemáticos Painlevé y Borel durante la Guerra de 1914 y del papel de Simiand y Halbwachs como miembros del Gabinete del Ministro de Armamento, Albert Thomas. 
El sorprendente ejercicio de revalorización de Halbwachs se hace de un texto, Le point de vue du nombre, poco conocido y valorado, lo más parecido a un fracaso en cuanto empresa editorial, que intentó sin éxito, bajo el frondoso paraguas de la Encyclopédie del siglo XX y la égida de Lucien Fevre, que lo mejor de los saberes del momento pudieran servir a un público informado de valladar a la amenazante ascensión de los fascismos. Un ascenso que arropaba su expansión ideológica en la cientificidad de las nuevas aproximaciones a la historia de los pueblos, la importancia de las razas en los conflictos geopolíticos o la relevancia de la eugenesia y las políticas demográficas. Brian y Jaisson después de describir el proyecto editorial en su contexto social y político (2005b, 9-23), contextualizan el significado, la estrategia y las disonancias de la asociación de Halbwachs en este proyecto con los jóvenes polytechniciens de la oficina estadística francesa (2005a, 53-71), representados principalmente por Alfred Sauvy ${ }^{35}$.

Brian centra su análisis metodológico en un asunto peculiar ${ }^{36}$ : la interpretación de un sorprendente resultado estadístico, la de las proporciones de hombres y mujeres al nacimiento. Observadas desde hace centurias, su llamativa constancia en todos los países, grupos y épocas, su ligera pero sistemática desviación del $50 \%$ en favor de los hombres, así como sus intrigantes diferencias entre ámbitos geográficos y momentos históricos, han sido un desafío interpretativo que ha tentado tanto a grandes pensadores, como a apasionados de la estadística o todo tipo de eruditos curiosos. No entraremos aquí en el documentadísimo repaso histórico de la cuestión que hacen Rohrbasser y Brian (2005, 73-84) y Brian y Jaisson (2005c, 85-99) por el que desfilan Graunt, Petty, Leibniz, Susmilch, Arbuthnot, D'Alambert, Laplace, Bayes, Condorcet, Hofaquer, Sadler, Poisson, Quetelet, Darwin o Legoyt, evaluando en cada caso argumentos providencialistas y probabilistas, la diferente apoyatura empírica sobre las que se apoyan los distintos autores y el aprovechamiento al que someten la incipiente producción estadística demográfica.

Halbwachs retoma en Le point du vue du nombre los razonamientos más extensos de su anterior artículo de $1933 b^{37}$ en el que postula la génesis probabilista de del fenómeno, pero en paralelo se lanza (como en tantos temas) a la búsqueda de una explicación causal de las diferencias, para terminar postulando que dicha explicación estaría asociada a las diferencias de edad entre los padres, y su evolución diferencial por territorios y cíclica en el tiempo. Con ello Halbwachs había coronado su objetivo: combinar el comportamiento aleatorio y causación social de las diferencias, pero dicha explicación no tardó en ser desmentida por los resultados de las estadísticas demográficas de todos los países. Hasta aquí, simplemente un caso más de arriesgada sobreinterpretación estadística no verificada posteriormente, en un contexto en el que las herramientas pearsonianas no

35 Junto a Henri Ulmer y Georges Bournier.

36 Posteriormente ampliado y reelaborado en Brian y Jaisson (2007a) y, desde distintos puntos de vista en Brian y Jaisson (2007b).

37 Halbwachs (1933b), reproducido en la edición del INED de Le point de vue du nombre (381-404).

EMPIRIA. Revista de Metodología de Ciencias Sociales. N. ${ }^{\circ} 43$ mayo-agosto, 2019, pp. 213-254.

ISSN: 1139-5737, DOI/ empiria.43.2019.24304 
estaban consolidadas. Lo más interesante es la construcción interpretativa que Brian y Jaisson trenzan alrededor de este asunto y de su conocimiento de toda la obra de Halbwachs. Lo hacen desde varias perspectivas.

Primeramente, Jaisson y Marcel sostienen la esencial unidad de la metodología halbwachsiana de investigación social, en la que el mundo del análisis estadístico de los comportamientos sociales (su morfología social) y las investigaciones psicológicas sobre los marcos sociales de la memoria no están disociados. Es precisamente su familiaridad con la matemática probabilista (a través de su relación con Frechet y su atenta lectura de Leibniz, Bernouille y Laplace) la que proporciona el gozne sobre el que gira su visión integra ${ }^{38}$. Solo dos profundos conocedores de cada una de los dos frentes de la obra halbwachsiana, como Jaisson y Brian, han podido aportar esta visión que estructura y enhebra las dos grandes ramas de la producción intelectual de Maurice Halbwachs. La hipótesis interpretativa además es tan sorprendente como fecunda, ya que, sin negar la impermeabilidad de Halbwachs en relación con lo que la obra canónica de Stigler denominó "revolución estadística" ${ }^{39}$, hace de su formación probabilista la clave sobre la que reposa el arco de su amplia pero coherente construcción intelectual.

Desde una segunda perspectiva Brian y Jaisson observan la relación entre estadística y morfología. Es la existencia de una regularidad en las desviaciones del azar lo que permite mostrar la marca de un hecho social, actuante como estructurador de comportamientos no arbitrarios. Cada sociedad opera como una totalización de las experiencias aleatorias que le es propia, una morfología por acumulación de las interacciones entre los individuos (Marcel y Jaisson, 2005, 106-7).

38 "On mesure ici à quel point le souvenir de l'œuvre de Halbwachs «est compris à la fois dans deux cadres; mais [que] l'un de ces cadres [...] empêche voir l'autre, et inversement» \{la referencia de los autores es : Halbwachs, La Mémoire collective (1997), p. 74$\}$... Il importe donc de mettre en évidence comment la Morphologie sociale, d'une part et la Mémoire collective, d'autre part pouvait chez le même auteur s'accorder au point de vue du nombre, de sorte qu'il entendit consacrer au Collège de France à la première son séminaire et à la seconde son cours magistral, les deux sous l'égide d'une même chaire intitulée «Psychologie collective». Le point de vue du nombre se prête en effet à un tel examen. C'est d'une part une étape du chemin qui conduit de la synthèse sur Les Causes du suicide (1930) au livre de méthode intitulé Morphologie social (1938c). C'est aussi, on vient de voir, un moment de la formation de la théorie halbwachsienne du hasard, et c'est là l'une des clés de ses travaux sur Les Cadres sociaux de la mémoire (1925), puis de la Mémoire collective (1932-1944)» (Marcel y Jaisson, 2005, 101-2).

39 "The key to the rapid spread of statistical methods to experimental psychology had been the possibility of experimental design, the control of experimental conditions. In the social sciences, where this possibility apparently did not exist, the successful use of probability-based statistical methods did not come quickly; indeed it may be argued that the development is far from complete today. But beginning in the 1880s there was a notable change in the intellectual climate, as a series of remarkable men constructed an empirical and conceptual methodology that provided a surrogate for experimental control and in effect dissipated the fog that impeded progress for a century. The three principal contributors to this clearing of the air were Francis Galton, Francis Ysidro Edgeworth, and Karl Pearson. Separately, they would rate mention as important figures in the very different fields of anthropology, economics, and the philosophy of science; together they helped to create a statistical revolution" (Stiegler, 1986, 265-6). 
En homología con la anterior se puede observar una tercera perspectiva. La construcción de la memoria colectiva, en tanto que memoria individual socialmente construida (Jaisson, 1999), supone la emergencia a partir de la memoria puramente individual. En este caso el polo del puro azar, de la erraticidad completa está representado por el sueño, la combinación inconexa, según Halbwachs, de imágenes y secuencias fuera de la organización que presta a la conciencia individual el marco de las representaciones sociales, en el que las imágenes entran en todo tipo de combinaciones fruto del puro azar ${ }^{40}$.

En conclusión: "un même schéma de construction gouverne les objets de la morphologie sociale et ceux de l'étude de la mémoire collective. Ce schéma a été conçu pour sauver le phénomène social de l'affaiblissement du cadre statistique quetelésien fondé sur la moyenne et adopté par Émile Durkheim. Il a été gagné au prix d'une dialogue avec la statistique mathématique de l'entre-deuxguerres et d'un effort de clarification du raisonnement probabiliste en science sociale» (Marcel y Jaisson, 2005, 110; y Brian y Jaisson, 2005d, 144).

La contextualización del proceso de recepción y revalorización de la obra de Halbwachs y el repertorio de las cinco revisiones críticas sobre la metodología de su análisis social anteriormente presentados representa lo que conocemos como más relevante en la materia, con la dificultad que una selección de este tipo tiene ante el inabarcable océano de producción sobre Halbwachs que existe en este momento. Estas consideraciones también permiten aportar los elementos que consideramos esenciales para ayudar al lector en español de las recensiones de Halbwachs sobre la gran obra de Keynes. Se trataba de mostrar que el análisis del cómo, de la metodología de investigación social de Halbwachs, es necesario no solo para interpretar adecuadamente su visión de Keynes, sino para centrar adecuadamente toda la obra de Halbwachs y su recuperación reciente. Como observará el lector, los textos ahora traducidos van a plantear una crítica básicamente metodológica, por otra parte, casi la única posible desde la perspectiva de Halbwachs, considerando el desierto de material empírico que es The General Theory.

En el optimismo inicial de nuestro plan de trabajo habíamos vislumbrado la posibilidad de avanzar sobre una comparación entre las categorías conceptuales de los dos gigantes del análisis social ${ }^{41}$ y sobre lo clave de este debate metodológico para el análisis de las crisis de 1929 y de 2008. Hoy como ayer, el papel del análisis económico y social se sitúa en cada inescapable coyuntura histórica como generador herramientas conceptuales y aproximaciones metodológicas, que permita mostrar las siempre parciales y relativas verdades sobre cada reali-

${ }^{40}$ Según Annie Topalov $(2011,204)$ Halbwachs había leído a Freud, pero no parece haber integrado su principal conclusión analítica: el sueño no como caos de acontecimientos, sino como testimonio de deseos sofocados a la vida consciente, aunque luego en su texto traza una serie de analogías entre la memoria halbwachsiana y freudiana.

${ }_{41}$ Sin renunciar a otras perspectivas y préstamos, como lo hacen de forma iluminadora Maris y Dostaler 2010). 
dad. El tiempo transcurrido y el esfuerzo dedicado nos han forzado a considerar que debemos, al menos, aplazar por el momento tal esfuerzo. No parece sensato ampliar la extensión de este dilatado texto introductorio y, por otra parte, prolongar este apartado con una revisión cruzada de todos los aspectos mencionados en las revisiones metodológicas, lo que además requeriría la vuelta a los textos de las principales obras de Halbwachs y un análisis pausado de la obra de Keynes y de su todavía más oceánica literatura crítica disponible. Nuestra inacabada tarea tiene la ventaja de que permite al lector extraer por sí mismo las enseñanzas que nos proporciona el observar, a través del espejo de unos analistas y testigos de excepción, las herramientas de análisis social y su interrelación con el devenir del proceso económico e histórico, observando igualmente en un segundo espejo las particularidades de aquella crisis de los años 30 del siglo XX y de la nuestra más reciente a partir de 2008.

Esperamos en todo caso haber cumplido nuestra principal tarea, que no era otra que la de estimular al lector para que disfrute y se aproveche de estos textos, tan breves como relevantes.

\section{BIBLIOGRAFÍA}

ALONSO, Luis Enrique e IBÁÑEZ ROJO, Rafael (2008), "Maurice Halbwachs y el desarrollo de la sociología del consumo y las necesidades en Francia" en Anthropos 218, 175-195.

ÁLVARER URÍA, Fernando (2017), "Presentación; Por la laicidad: los marcos sociales de a sociología de la religión de Émile Dukheim y su escuela" en Maurice Halbwachs, Los orígenes del sentimiento religioso según Durkheim. Introducción a la sociología de la religión de Émile Durkheim, Madrid, Dado Ediciones, 9-102.

AMIOT, Michel (1991), «Le système de pensée de Maurice Halbwachs», Revue de Synthèse, 265-288.

ARRIBAS MACHO, José María (2008), "Maurice Halbwachs y la estadística" en Anthropos 218, 120-136.

BAUDELOT, Christian y ESTABLET, Roger (1994), Maurice Halbwachs. Consommation et société, París, Presses Universitaires de France.

BECKER, Annete (2003), Maurice Halbwachs. Un intelectuel en guerres mondiales 1914-1945, París, Agnes Viénot Editions.

BOURDIEU, Pierre (2008), "El asesinato de Halbwachs" en Anthropos 218, 43-47.

BRIAN, Éric (2005a), «Comment contrôler le sexe des enfants? Documents sur une obsession statistique au sein de la SS», en HALBWACHS, Maurice; SAUVY, Alfred; ULMER, Henri; BOURNIER, Georges Le point de vиe du nombre, 149-168.

BRIAN, Éric (2005b), «Comment contrôler le sexe des enfants? Documents sur une obsession statistique au sein de la SS «, en HALBWACHS, Maurice; SAUVY, Alfred; ULMER, Henri; BOURNIER, Georges Le point de vиe du nombre, 149-168.

BRIAN, Éric; JAISSON, Marie (2005a), «Il fallait cette association... «, en HALBWACHS, Maurice; SAUVY, Alfred; ULMER, Henri; BOURNIER, Georges Le point de vue du nombre, 53-71. 
BRIAN, Éric; JAISSON, Marie (2005b), «Coup d'oeil sur 'L'Encyclopédie française'», en HALBWACHS, Maurice; SAUVY, Alfred; ULMER, Henri; BOURNIER, Georges Le point de vue du nombre, 9-23.

BRIAN, Eric; JAISSON, Marie (2005c), «La Filiation physiologique du sexe à la naissance». En HALBWACHS, Maurice; SAUVY, Alfred; ULMER, Henri; BOURNIER, Georges Le point de vue du nombre, 85-99.

BRIAN, Éric ; JAISSON, Marie (2005d), «Nombre et mémoire. Halbwachs sociologue probabiliste", en KRAPOTH, Hermann; LABORDE, Denis (Hrsg.) Erinnerung und Gesellschaft. Mémoire et Société», 127-151.

BRIAN, Éric; JAISSON, Marie (2007a), Le sexisme de la première heure. Hasard et sociologie, Paris, Raisons d'agir.

BRIAN, Éric; JAISSON, Marie (2007b), The Descent of Human Sex Ratio at Birth. A Dialogue between Mathematics, Biology and Sociology, Springer, Dordrecht

CARBALLO, RODRÍGUEZ, Francisco Manuel (2017), « Maurice Halbwachs y la estadística en sociología » en Encrucijadas. Revista Crítica de Ciencias Sociales, vol.

13, tc1301, 1-7.

COSER, Lewis (1992), "Introduction. Maurice Halbwachs 1877-1945” en Maurice Halbwachs, On Collective Memory, Chicago, University of Chicago Press, 1-34

DESROSIÈRES, Alain (1985), «Histoires de formes, statistiques et sciences sociales avant 1940», Revue Française de Sociologie, 277-310.

DOUGLAS, Mary (1980), "Introduction. Maurice Halbwachs (1877-1945)" en Maurice Halbwachs, The Collective Memory, Nueva York, Harper and Row, 1-22.

FRÉCHET, Maurice; HALBWACHS, Maurice (1924), Le Calcul des probabilités à la portée de tous, Paris, Dunod

GIERL, Walter; BRIAN, Éric (2005), «La réception de la démographie de Halbwachs sous le IIIe Reich», en HALBWACHS, Maurice; SAUVY, Alfred; ULMER, Henri; BOURNIER, Georges Le point de vue du nombre, 131-148.

GONZÁLEZ ALCANTUD, José Antonio (2009), "Maurice Halbwachs en España, reflexividad sobre una ausencia", Historia, antropología y fuentes orales 41, 81-94.

GURVITCH, Georges (1976), La vocation actuelle de la sociologie, París, Presses Universitaires de France, 2 vols.

HALBWACHS, Maurice (1909), Les Expropriations et les prix des terrains à Paris (1860-1900), Paris, Cornély.

HALBWACHS, Maurice (1912), La classe ouvrière et les niveaux de vie. Recherches sur la hiérarchie des besoins dans les sociétés industrielles contemporaines, Paris, Librairie Felix Alcan.

HALBWACHS, Maurice (1913), La théorie de l'homme moyen. Essai sur Quetelet et la Statistique Morale, Paris, Librairie Felix Alcan.

HALBWACHS, Maurice (1928), La population et les tracés de voies à Paris depuis un siècle, Paris, Presses Universitaires de France.

HALBWACHS, Maurice (1930), Les causes du suicide, Paris, Librairie Felix Alcan

HALBWACHS, Maurice (1933a), L'évolution des besoins dans les classes ouvrières, Paris, Librairie Felix Alcan.

HALBWACHS, Maurice (1933b), «Recherches statistiques sur la détermination du sexe à la naissance», Journal de la Société Statistique de Paris, 164-191.

HALBWACHS, Maurice (1936 [2005]), «Recherches statistiques sur la détermination du sexe à la naissance», en HALBWACHS, Maurice; SAUVY, Alfred; ULMER, Henri; BOURNIER, Georges Le point de vue du nombre, 381-404. 
HALBWACHS, Maurice (1938a), Analyse des mobiles dominants qui orientent l'activité des individus dans la vie sociale, Bruselas, Institut de Sociologie Solvay

HALBWACHS, Maurice (1938b), "Keynes (J.M.), 'The General Theory of Employment, Interest, and Money (London, Macmillan, 1936, XII-403 p.)", Annales sociologiques, 25-41.

HALBWACHS, Maurice (1938c), Morphologie sociale, Paris, Armand Colin

HALBWACHS, Maurice (1938d), "Robinson (Joan), 'Essays in the Theory of Employment' (London, Macmillan, 1937, VII-255p., in 8')", Annales sociologiques, 70-71.

HALBWACHS, Maurice (1940a), «La 'Théorie générale' de John Maynard Keynes», Annales sociologiques, 25-41.

HALBWACHS, Maurice (1940b), «Keynes et son école», en Sociologie Économique et Démographie, Paris, Hermann et $\mathrm{C}^{\mathrm{ie}}$. Editeurs, 9-19 [es un capítulo y no un texto bibliográficamente independiente].

HALBWACHS, Maurice (1940c), Sociologie Économique et Démographie, Paris, Hermann et $C^{\mathrm{ie}}$. Editeurs.

HALBWACHS, Maurice (1943), «La population d'Istanbul (Constantinople) depuis un siècle», Annales Sociologiques, serie E, 3-4, 16-43.

HALBWACHS, Maurice (1944 [1935]), «La Statistique en sociologie», en HUBER, Michel; BOREL, Émile; PIGANIOL, André; ESMONIN, Ed.; HALBWACHS, Maurice; LEVY-BRUHL, Henri; VAN TIEGHEM, Philippe; DARMOIS, George; TEISSIER, Georges, La Statistique. Ses applications. Les problèmes qu'elles soulèvent, 113-134.

HALBWACHS, Maurice (1950 y 1964), Las clases sociales, Fondo de Cultura Económica, México

HALBWACHS, Maurice (1955), Esquisse d'une psychologie des classes sociales, Paris, M. Rivière.

HALBWACHS, Maurice (1964), Las clases sociales, México, Fondo de Cultura Económica, $3^{\mathrm{a}}$. Ed.

HALBWACHS, Maurice (1972 [1937]), «Le point de vue du sociologue», en HALBWACHS, Maurice, Classes sociales et morphologie, 390-408.

HALBWACHS, Maurice (2001[1950]) La Mémoire Collective, París, Alcan, edición electrónica recuperada en http,//bibliotheque.uqac.uquebec.ca/index.htm

HALBWACHS, Maurice (2008a [1937]), Les classes sociales, Paris, Presses Universitaires de France.

HALBWACHS, Maurice (2012), Écrits d’Amérique, París, Éditions de l'EHESS. Edición de Christian Topalov.

HALBWACHS, Maurice (2016), Keynes, abstraction et expérience. Sur la Théorie générale, París, Éditions Rue d' Ulm, Édition de Gilles Montigny.

HALBWACHS, Maurice; SAUVY, Alfred; ULMER, Henri; BOURNIER, Georges (1936 [2005]), Le point de vue du nombre, Paris, Institut National d'Études Démographiques.

HJELLBREKKE, Johns (2007), "Maurice Halbwachs", en SCOTT, John (Ed.) Fifty Key Sociologists. The Formative Theorists, Londres y Nueva York, Routledge, 61-64.

HUICI URMENETA, Vicente (2007), Espacio, tiempo y sociedad. Variaciones sobre Durkheim, Halbwachs, Gurvitch, Foucault, Bourdieu, Madrid, Akal.

JAISSON, Marie (1999), «Temps et espace chez Maurice Halbwachs (1925-1945) «, Revue d'histoire des sciences humaines, 163-178.

JAISSON, Marie y BAUDELOT, Christian (eds.) (2007), Maurice Halbwachs, sociologue retrouvé, París, Éditions Rue d'Ulm. 
KEYNES, John Maynard (1973 [1936]), The General Theory of Employment, Interest and Money, London, Macmillan Cambridge University Press

MARCEL, Jean-Christophe, JAISSON, Marie (2005), «Morphologie et mémoire», en HALBWACHS, Maurice; SAUVY, Alfred; ULMER, Henri; BOURNIER, Georges Le point de vue du nombre, 101-110.

MARIS, Bernard; DOSTALER, Gilles (2010), Capitalisme et pulsion de mort. Quand Freud rencontre Keynes, Paris, Fayard / Pluriel

MARTÍNEZ GUTIÉRREZ, Emilio (2008a), "Las expropiaciones y la especulación del suelo, entre perspectiva sociológica y la estrategia reformista” en Anthropos 218, 137 152.

MARTÍNEZ GUTIÉRREZ, Emilio (2008b), “Presentación, morfología social y memoria de la ciudad”, en Maurice Halbwachs, Estudios de morfología social de la ciudad, Madrid, Centro de investigaciones Sociológicas.

MARTÍNEZ GUTIÉRREZ, Emilio (2016), "Morfología social y demografía en Maurice Halbwachs", en Empiria 33, 175-184

MONTIGNY, Gilles (2005), Maurice Halbwachs. Vie, ouvres, concepts, París, Ellipses.

MONTIGNY, Gilles (2016), "Introduction" a Maurice Halbwachs, Keynes, abstraction et expérience. Sur la Théorie générale, París, Éditions Rue d’ Ulm, 11-61.

PFEFFERKORN, Roland (1997), "Maurice Halbwachs et l'économie politique, en MONTIBERT, Christian de (Ed.), Maurice Halbwachs 1877-1945. Strasbourg, Presses Universitaires de Strasbourg.

RAMOS, Ramón (2014), "Prefacio a la edición en español” en Maurice Halbwachs, La topografía legendaria de los evangelios en Tierra Santa. Estudio de memoria colectiva, Madrid, Centro de Investigaciones Sociológicas, 9-24.

ROCH, Fernando (2008), "El problema del precio de la vivienda. Morfología social y memoria colectiva" en Anthropos 218, 153-174.

ROHRBASSER, Jean-Marc BRIAN, Éric (2005), «Histoire de la preuve par le nombre des naissances», en HALBWACHS, Maurice; SAUVY, Alfred; ULMER, Henri; BOURNIER, Georges Le point de vue du nombre, 73-83.

ROSAVALLON, Pierre (1987), "Histoire des idées keynésiennes en France”, en Revue Française d'Économie, vol II, núm 4, 22-56

SEMPRÚN, Jorge (1995), La escritura o la vida, Tusquets, Barcelona

STEINER, Philippe (1999a), La Sociologie économique, París, La Decouverte.

STEINER, Philippe (1999b), «Maurice Halbwachs, les derniers feux de la sociologie économique durkheimienne», Revue d'histoire des sciences humaines, 141-162.

STEINER, Philippe (2005), L'École durkheimienne et l'économie, sociologie, religion et connaissance, Ginebra, Droz.

STEINER, Philippe (2008), «La tradition française de critique sociologique de l'économie politique», Revue d'histoire des sciences humaines, 63-84.

STIGLER, Stephen M. (1986), The History of Statistics. The Measurement of Uncertainty before 1900, Cambridge, Harvard University Press

TOPALOV, Annie (2011), «Freud avec Halbwachs : les conditions d'une inscription symbolique», Le Coq-Herón, 154-159.

TOPALOV, Christian (1997), «Maurice Halbwachs et les villes (1908-1912). Une enquête d'histoire sociale des sciences sociales», Annales. Histoire, Sciences Sociales, 1057-1083.

TOPALOV, Christian (1999), «'Expériences sociologiques’, les faits et les preuves dans les thèses de Maurice Halbwachs (1909-1913) «, Revue d'histoire des sciences humaines, 
$11-46$.

VERRET, Michel (1972), «Halbwachs ou le deuxième âge du durkheimisme», Cahiers Internationaux de Sociologie, 312-336. 


\section{KEYNES Y SU ESCUELA ${ }^{42}$}

\section{MAURICE HALBWACHS}

Entre las grandes corrientes del pensamiento económico contemporáneo, la Escuela de Cambridge merece mención aparte; si bien hasta hace poco había estado principalmente representada por Alfred Marshall y Arthur Pigou, en la actualidad su más famoso representante es John Maynard Keynes. Tras A Tract on Monetary Reform (1923; traducción española: Breve tratado sobre la reforma monetaria) y su gran obra A Treatise on Money (2 volúmenes, 1930; Tratado sobre el dinero), recientemente ha publicado The General Theory of Employment, Interest and Money (London, MacMillan, 1936, XII-403 p., in- $8^{\circ} ;$ La teoría general del empleo, el interés y el dinero), acogida con gran entusiasmo por los jóvenes economistas de esta escuela. Las revistas inglesas han disertado largo y tendido en torno a esta obra y han surgido numerosos discípulos que se han inspirado en ella en múltiples artículos y libros.

Y es que Keynes, fiel seguidor de hecho del método dialéctico abstracto, en el que llega incluso mucho más lejos que los clásicos, ha pretendido sin embargo renovar sus conceptos, abordando un problema muy actual: el empleo de la mano de obra y el paro; de ahí su ampliación y flexibilización de las teorías tradicionales, así como su marcada orientación práctica, sin apartarse por ello no obstante de la línea de pensamiento deductivo propia de los más notables economistas clásicos británicos a lo largo de todo el siglo XIX y hasta nuestros días. Parece de hecho, como ya se le ha reprochado, haber ignorado sistemáticamente todo lo ajeno a este pensamiento un tanto cerrado y a este método no siempre fácil de comprender más allá de un pequeño círculo de iniciados.

Intentemos, sin embargo, hacernos una idea de esta obra. Lo primero es una definición del pleno empleo (full employement) que sería el objetivo principal a lograr, pues el progreso económico resultaría de otra manera inconcebible. El full employment, nos dice Keynes, se consigue cuando existe una igualdad entre el salario real y la disutility marginal del empleo. El salario real se distingue del salario nominal o en moneda en que representa los bienes consumibles que se pueden comprar con la retribución ofrecida por un trabajo. La disutility del empleo consiste en todas las razones que pueden conducir a una persona o grupo a no ofrecer su trabajo por un salario cuya utilidad para ellos sea inferior a un mínimo. De lo que resulta que se produce full employment cuando el salario ofrecido permite a todo obrero alcanzar dicho mínimo. En tal caso, ya no habría parados o más bien, como pensaban los clásicos, solo habría parados voluntarios.

La principal objeción planteada por Keynes contra esta teoría es la siguiente: la teoría tradicional pretende que las negociaciones entre empresarios y trabajadores en torno al salario nominal determina el salario real, desde el momento en que estos puedan igualar dicho salario real a sus exigencias mínimas. Esto en un sistema cerrado. Pero es algo que viene a contradecir la tesis clásica, a saber: que los precios resultan del coste de producción en términos monetarios. Si los salarios nominales cambian, los precios también lo hacen en la misma proporción y sentido, por lo que los salarios reales y la cantidad de empleo por lo tanto no cambian. Así que el tabajo carece de la posibilidad de ajustar el salario real a un nivel dado mediante la revisión de los salarios nominales. Pero hay otras fuerzas que determinan el nivel general de los salarios reales. Resulta de hecho afortunado que los trabajadores no se opongan al aumento del coste de la vida, pues esto supondría un obstáculo al aumento del conjunto del empleo.

En realidad, el paro involuntario, que la teoría clásica no creía posible, se produce sin embargo cuando, en caso de un leve aumento de los precios de los bienes comprados en relación

${ }^{42}$ Keynes et son école" apareció en 1940 Sociologie économique et démographie la Editorial Hermann de París (pp. 9-19), Reimpresa en Maurice Halbwachs, Keynes, abstraction et expérience. Sur la Théorie génerale, París, Édtions Rue d' Ulm, pp. 68-80. De donde la reproducimos. Traducción de Eric Jalain, revisada por Luis Enrique Alonso e Ignacio Duque. 
con el salario nominal, la oferta total de trabajo que consiente emplearse por el salario nominal en curso y la demanda total de trabajo por dicho salario resultan superiores al volumen de empleo existente. Dicho de otra manera, se puede constatar que, en las condiciones económicas presentes, aunque los obreros consientan a reducir un poco sus exigencias y los empresarios a conservarlos o contratarlos por el mismo salario, muchos obreros acaban privados de trabajo porque resulta imposible utilizar esta mano de obra excedentaria.

Esto es así porque el volumen de empleo depende de lo que Keynes denomina la función de la demanda total, es decir, del total de ingresos, que determina el poder adquisitivo. David Ricardo pensaba, a decir de Keynes, que esta función de la demanda total podía ser pasada por alto. «Ricardo conquistó Inglaterra tal como la Santa Inquisición conquistó España. Logró una gran autoridad gracias a que pudo explicar numerosas injusticias sociales y crueldades aparentes como accidentes inevitables en la marcha del progreso, y a que sostuvo que los intentos de cambiar todas estas cosas podían, a fin de cuentas, acabar haciendo más mal que bien. Así como gracias a que justificó las libres actividades del capitalista individual.» Sin embargo, sus planteamientos nunca han permitido elaborar previsiones científicas.

Partamos ahora del dividendo nacional (D) que mide el volumen de la producción. (D) se compne de consumo $\left(\mathrm{D}_{1}\right)$ e inversión $\left(\mathrm{D}_{2}\right)$; en empleos relacionados con el consumo y en empleos reproductivos. Cuando el empleo aumenta, el consumo $\left(\mathrm{D}_{1}\right)$ también aumenta, pero no en la misma medida que (D). Según Keynes, la clave de todo el problema es una ley psicológica. Cuanto más aumenta el empleo, más lo hace también el intervalo entre el precio total de oferta $(\mathrm{Z})$ de la producción y el montante $\left(\mathrm{D}_{1}\right)$ que los empresarios pueden esperar que los consumidores se gasten. Por lo tanto, es necesario que las inversiones $\left(\mathrm{D}_{2}\right)$ también aumenten (la teoría clásica pretende que $\mathrm{D}_{2}$ siempre aumenta lo suficiente para cubrir este intervalo, y en esto se equivoca). Por lo tanto, puede producirse un equilibrio estable por debajo del full employment. En otras palabras, en esta situación puede ocurrir que el nivel de salario real resulte más elevado que la disutility marginal, es decir, que el salario por el cual los obreros en paro aceptarían trabajar.

De ahí la paradoja de la pobreza en plena abundancia. Una demanda efectiva insuficiente puede detener el aumento del empleo antes de llegar al full employment (es decir, cuando el producto marginal del trabajo, o de la última unidad de trabajo empleada, aún supera en términos de valor el punto a partir del cual el empleo deja de resultar útil). Cuanto más rica es una comunidad, más amplio tiende a ser el intervalo entre su producción real y potencial. Pues una comunidad pobre tiende a consumir la mayor parte de su producción, por lo que bastan unas inversiones muy reducidas para asegurar el pleno empleo. Una comunidad rica, por el contrario, debe contar constantemente con oportunidades de inversión cada vez más amplias para que la tendencia a economizar de sus miembros más adinerados resulte compatible con el empleo de sus miembros más pobres. Si la incitación a la inversión es escasa, va a tender a reducir su producción real hasta que se empobrezca tanto que su excedente de consumo se corresponda con la debilidad de su tendencia a invertir. Es más, no solo la propensión al consumo resulta más débil en una comunidad rica, sino que además, como ya existe una gran acumulación de capital, las oportunidades de futuras inversiones resultan menos atractivas, a no ser que la tasa de interés (por el préstamo de dinero) disminuya de forma bastante rápida.

Así, el análisis de la propensión al consumo, la definición del rendimiento marginal del capital y la teoría de la tasa de interés constituyen pues las tres lagunas que vamos a explorar.

Analicemos primero la propensión al consumo (propensity to consume), que es una de las nuevas variables introducidas por Keynes en la teoría económica. El consumo está relacionado con el ingreso neto. Cuanto mayor sea la reserva financiera previa necesaria hasta la recepción del ingreso neto, menos favorable al consumo, y por lo tanto al empleo de mano de obra, será el nivel de inversión correspondiente.

Imaginemos por ejemplo una casa para la cual se aparta cierto dinero todos los años, con la intención de reconstruirla algún día, pero que mientras tanto no se va manteniendo. En una economía no estática, durante un periodo de gran abundancia de inversiones en capital de larga duración, una gran parte de las nuevas inversiones puede ser absorbida por las amplias reservas financieras realizadas por empresarios, debido al equipamiento en capital existente: la idea consiste en prever las reparaciones y la renovación de dicho capital, pero (aunque se desgaste con el paso 
del tiempo) se pospone el momento de gastar algo, acercándose así a una acumulación plena de las reservas financieras; de ello resulta que las rentas no pueden elevarse por encima de un nivel bastante bajo, correspondiente a un total escaso de nuevas inversiones. Todos estos fondos inmovilizados en reservas menguan el poder adquisitivo de los consumidores mucho antes de que se recupere la demanda relacionada con gastos en remplazos (anticipados por estas reservas). La demanda efectiva solo aumenta así el año en que se efectúan los remplazos. Un exceso de prudencia financiera puede incluso agravar todo esto, cuando se juzga conveniente amortizar el coste inicial en un plazo de tiempo inferior al desgaste del equipamiento.

Esto es lo que se pudo observar en Estados Unidos en 1929 y, más recientemente, en Gran Bretaña en 1935. Se constituyeron reservas estatutarias de autoridades públicas y semipúblicas, disociadas de toda nueva inversión, hasta más de la mitad del importe gastado en vistas a la creación de nuevas empresas, lo que agravó especialmente el problema del desempleo (aquí Keynes se apoya en las cifras presentadas por Simon Kuznets para Estados Unidos entre 1919 y 1933). La población suele estar de acuerdo, por lo general, en lo relativo a la conveniencia de las inversiones públicas, como la construcción de carreteras y casas, dependencias municipales, instalaciones de agua, etc. Es consciente del inconveniente real de inmovilizar grandes sumas en previsión de gastos lejanos. Pero, en el caso de las inversiones privadas ocurre exactamente lo mismo; el capital no es una entidad que se agote en sí misma, independientemente del consumo.

Se puede incrementar el consumo desarrollando el poder adquisitivo, es decir, incrementando el empleo (de mano de obra), pero esto supone que también aumentarían las inversiones. Queda así claro hasta qué punto los gastos basados en préstamos pueden enriquecer a la comunidad; desde la construcción de pirámides, nos dice Keynes, hasta los terremotos o las guerras pueden así incrementar la riqueza. El sentido común no se equivoca y parece aceptable que los seguros de paro sean financiados mediante préstamos (en vez de que sea el Estado quien financie mejoras por debajo de las tasas corrientes de interés). «La mejor solución parece ser la explotación de las minas de oro, que nada añaden a la riqueza del mundo. El antiguo Egipto era así doblemente afortunado, pues se basaba en dos actividades: la construcción de pirámides y la búsqueda de metales preciosos, cuyos frutos no eran destinados al consumo, por lo que no se depreciaban debido a su abundancia. Pero ahora nos hemos vuelto excesivamente prudentes, por nuestro celo de no añadir peso al fardo financiero de las futuras generaciones (es como si nos dedicáramos ya a apartar dinero para que puedan construirse sus casas). Y debemos soportar las miserias del paro porque aplicamos al Estado las máximas más adecuadas para enriquecer a un individuo, permitiéndole acumular títulos que no tiene intención de utilizar en ningún momento concreto.»

Keynes hace aquí referencia a toda una política financiera propia de la tradición puritana, que insiste en la virtud del ahorro puro y duro, del ahorro improductivo. Como nos recuerda Étienne Mantoux, en su estudio sobre la teoría general de Keynes («La Théorie générale de M. Keynes», Revue d'économie politique, noviembre-diciembre de 1937, pp. 1559-1590), este siempre habla con ironía del deber del ahorro. Nunca pensó que «las siete maravillas del mundo» fueran «construidas a base de ahorrar». Hay que tener en cuenta, nos dice además, que economizar -así como gastar, de hecho- es una actitud o una acción que se puede considerar desde dos aspectos: con respecto al individuo, que parece libre de economizar cuanto quiera, sin tener en cuenta lo que él mismo u otros inviertan, pues en cualquier caso la suma de sus ahorros carece indudablemente de una influencia relevante sobre sus propios ingresos; pero también se puede considerar con respecto a los demás, donde en cambio se puede percibir que la reducción del consumo afecta a los ingresos de otras personas, de manera que resulta imposible que todos los individuos ahorren a la vez ciertas sumas. En su aspecto colectivo, todo intento de incrementar el ahorro reduciendo el consumo afecta a los ingresos de manera que el proceso se autodestruye. Resulta además igual de imposible, evidentemente, que una comunidad ahorre menos que la suma de las inversiones corrientes.

Pasemos ahora a analizar la incitación a ahorrar o a invertir. Comencemos definiendo la eficacia marginal del capital: se trata de la relación entre el rendimiento esperado de una unidad nueva del capital y el coste necesario para producir dicha unidad. El rendimiento corresponde a la serie de las anualidades esperadas durante la vida del capital. La escala de la demanda de capitales para inversión nos indica cuánto debe aumentar esta para un tipo específico de capital antes de 
que su rendimiento marginal caiga por debajo de un nivel determinado. De lo que se deduce esta fórmula esencial: la tasa de inversión aumentará hasta donde la eficacia marginal del capital iguale a la tasa de interés fijada en el mercado.

¿Pero cómo determinar el rendimiento esperado, es decir, las anualidades futuras? La psicología de los negocios nos enseña que la tendencia es a basarse sobre todo en el presente, como si el estado de cosas existente fuera a prolongarse indefinidamente. Se puede, como mucho, pretender anticipar algunos meses, pero nunca a evaluar el rendimiento en un plazo futuro de varios años. La tendencia es, en suma, a basarse en la opinión de los demás, o más exactamente, en cómo cree cada uno que será esa opinión. Como en esos concursos de los periódicos en los que los concursantes deben elegir las seis fotografías más atractivas entre cientos de ellas. Normalmente se reducen a señalar no tanto las fotografías que cada uno halla más atractivas como las que cada uno piensa que resultan más atractivas a los demás (haciendo cada uno, de hecho, el mismo cálculo). Pero nada garantiza que la inversión considerada por todo el mundo como la más ventajosa resulte realmente la más beneficiosa.

La teoría general de la tasa de interés aquí presentada constituye una de las partes más originales de toda esta construcción. Es puramente monetaria (a diferencia de la teoría de Knut Wicksell, que Keynes había adoptado anteriormente). Keynes distingue dos tipos de tasas: por un lado, la eficacia marginal del capital, tasa equivalente al valor presente de las anualidades producidas por un capital determinado y su coste de reposición, límite del precio que los empresarios estarían dispuestos a pagar; por otro lado, la tasa de interés, que es la demandada por los prestamistas a cambio de una suma de dinero en efectivo. La primera tasa no expresa una relación de productividad real, solo el efecto de las previsiones y va disminuyendo a medida que aumenta el volumen total del capital invertido (pues mientras el coste de reposición aumenta, el rendimiento esperado disminuye). El volumen de las inversiones se ajusta al punto donde la eficacia marginal del capital coincide exactamente con el nivel de la tasa de interés corriente.

Pero la tasa de interés no depende de la oferta y demanda de ahorros, ni de factores psicológicos, de abstinencia o de time-preference, sino de «la preferencia de liquidez» (nueva función introducida por Keynes). Si una persona decide atesorar en efectivo, no recibe interés. El interés es por lo tanto el precio que equilibra el deseo de guardar el dinero en efectivo o la preferencia de liquidez y la cantidad disponible de moneda. Si la tasa de interés es muy baja, la cantidad de dinero en efectivo que la población quiere conservar puede llegar a superar a su oferta; si es muy elevada, puede darse un excedente de efectivo que nadie quiere guardar. De esta manera, la cantidad de moneda constituye el segundo factor (M) que se combina con la preferencia de liquidez (L) para determinar la tasa de interés (r); de ahí la siguiente fórmula: $\mathrm{M}=\mathrm{L}(\mathrm{r})$.

La preferencia de liquidez es pues una variable independiente, que responde a diversas motivaciones: 1) La motivación del ingreso, es decir, la preocupación por superar el intervalo de tiempo entre el devengo y el cobro del ingreso; 2) la motivación comercial, es decir, la preocupación por superar el intervalo de tiempo desde que se inicia un negocio y se recibe el producto del mismo, o bien entre la compra y la realización; 3) la motivación de la precaución; y 4) la motivación de la especulación. Toda persona que piense que en el futuro la tasa de interés va a ser más elevada que en el mercado actual, tiene una buena razón para conservar dinero en efectivo. Es la existencia de un mercado organizado lo que da pie al mercado especulativo.

A veces, esta función puede inclinarse en un sentido u otro de forma muy marcada debido a circunstancias bastante anormales. Tras la guerra, en Rusia y Europa central se produjo una crisis de circulación. Nadie se sentía motivado a guardar efectivo o depósitos deudas, e incluso una tasa de interés elevada y en sostenido crecimiento no lograba seguir el paso al rendimiento marginal del capital (especialmente de las reservas de bienes líquidos), puesto que todo el mundo se esperaba un desplome brusco de la moneda. En Estados Unidos, en ciertos momentos, especialmente en 1932, se han producido crisis financieras o de liquidez en un sentido opuesto, cuando casi nadie estaba dispuesto a deshacerse de efectivo en condiciones razonables.

Keynes ha mostrado que, con una tasa de interés a cero, hay (en las empresas de producción) un intervalo temporal óptimo para todo artículo entre la fecha media de puesta en marcha de su fabricación y su fecha de consumo, durante el cual el coste del trabajo es mínimo. Un proceso de producción más corto resultaría técnicamente menos eficaz, así como un proceso más largo, 
debido a los costes de almacenamiento y de deterioro. Pero si la tasa de interés supera a cero, interviene un nuevo factor de coste que se incrementa con la duración del proceso, de manera que el intervalo óptimo se ve reducido, así como el plazo previsto para la distribución del artículo, por lo menos hasta que su precio pueda aumentarse lo suficiente para cubrir los nuevos costes (tanto los derivados del interés como de la disminución de la eficacia debida al acortamiento de los plazos de producción). A esto Keynes añade: «Si me hallo en lo cierto al suponer que resulta relativamente fácil asegurar tal abundancia de capitales que el rendimiento marginal del capital sea cero, esto podría suponer la forma más perfeccionada de ir suprimiendo gradualmente gran número de los inconvenientes del capitalismo. Esto conllevaría la desaparición progresiva de la tasa de rendimiento (return) obtenida por la acumulación de riqueza. Pero toda persona seguiría siendo libre de acumular sus ganancias con el fin de gastarlas más adelante. Se hallaría en la situación del padre de Pope que, tras retirarse de los negocios, se llevó consigo una caja llena de guineas a su villa de Twickenham, para ir cubriendo así sus gastos a medida que se producían.» Seguiría habiendo beneficio (en el sentido estricto del término) empresarial, la parte correspondiente al riesgo (que puede, en su conjunto, dar rendimientos negativos). En todo caso, reducir la tasa de interés dependería de un banco central que ajustara la cantidad de moneda.

La experiencia nos dicta (aunque, como todo lo que precede, según Keynes, no parezca derivar de una necesidad lógica) que una característica de nuestro sistema económico consiste en que, si bien parece sujeto a fuertes fluctuaciones en lo referente a la producción y empleo, tampoco resulta excesivamente inestable. Parece de hecho capaz de permanecer, durante periodos muy prolongados, en una situación crónica de baja actividad. Es más, el pleno empleo (full employment), o prácticamente pleno, es raro y de corta duración. En cuanto a las fluctuaciones, pueden iniciarse bruscamente, pero parecen perder fuerza por sí mismas antes de llegar a extremos; lo mismo ocurre con los precios. Tanto el entorno como las tendencias psicológicas del mundo moderno también se corresponden a estos resultados. Pero no olvidemos que estamos hablando de datos de facto, no de principios, por lo que nada prueba que no podamos modificarlos.

La teoría clásica afirma que una reducción de los salarios nominales estimularía la demanda, al reducir los precios de los productos acabados y, en consecuencia, aumentaría la producción y el empleo hasta el punto de que esta reducción salarial aceptada acabaría siendo compensada por la reducción del rendimiento marginal. Pero según Keynes, al contrario, la política más conveniente consistiría en mantener estable el nivel general de salarios nominales, de lo que se derivaría una gran estabilidad en los niveles de precios. Esto a corto plazo. A largo plazo, lo mejor sería permitir que los salarios fueran aumentando lentamente, mientras se mantienen los precios estables (mejor que dejar caer los precios lentamente, debido a la aplicación de los progresos técnicos y al mantenimiento de unos salarios estables). Esta sería la mejor manera de acercarse al full employment. El Estado, por su lado, debería ejercer una influencia rectora en la propensión al consumo, en parte mediante su sistema fiscal, en parte mediante la fijación de la tasa de interés, o por otros medios.

La obra que acabamos de analizar supone un esfuerzo teórico de suma importancia. Pero, ¿qué es lo que nos está enseñando, a fin de cuentas?

Existe una oposición muy llamativa -no solo en cuanto a métodos, sino también en cuanto aresultados- entre esta teoría (los principios que pretende verificar, las conclusiones prácticas a las que llega) y la interpretación de la realidad económica tal como es expuesta por el maestro de la sociología económica positiva François Simiand. La gran diferencia entre uno y otro reside en que, según Simiand, lo que podemos constatar (y lo que indudablemente constituye la condición del progreso económico) no es tanto el equilibrio -equilibrio del empleo, de los precios, estabilidad en todos los ámbitos- como la sucesión o alternancia de fases que podríamos denominar desequilibrios, en sentidos de hecho diversos, el paso de una fase a otra en un movimiento continuo e irreversible, que se manifiesta en forma de obstáculos, deficiencias, imperfecciones, que lo más a menudo no son sino las condiciones de la actividad general, creaciones y organizaciones nuevas que no serían realizables ni concebibles de otra manera.

Se ha dicho que lo que caracteriza a la ciencia experimental moderna, con respecto a las físicas y metafísicas de la Antigüedad, es su mayor precisión tanto en cuanto a hipótesis como a observaciones. Las nociones e hipótesis de Keynes solo son formales; no se aplican a ninguna 
realidad observable. Aunque en bastantes partes de su obra aporte datos reales, tomados sobre todo de la evolución contemporánea, e incluso proponga frecuentemente ideas de investigaciones que podrían llevarse a cabo, todo esto no constituye, visiblemente, más que concesiones que tiene a bien realizar, un poco de pasada, para aquellos que gustan de ejemplos y hechos, es decir, para los espíritus positivos, pues él, en cambio, planea sobre regiones bien diferentes.

Joan Robinson, además de llevar a cabo un notable estudio sobre la «competencia imperfecta», también ha publicado Essays in the Theory of Employment (London, Macmillan, 1937, VII-255 p.; Introducción a la teoría del empleo), consistente en trece ensayos inspirados en la teoría de Keynes, retomando en parte artículos anteriormente publicados en el Economic Journal y en la Zeitschrift für Nationalökonomie. En ellos, viene a criticar los actuales proyectos de mitigación del paro y analiza los efectos de los diversos sistemas asistenciales, las interacciones entre el nivel monetario y el empleo, así como los métodos para transferir el paro al extranjero (¿toda política nacional de incremento del empleo no conlleva a menudo el riesgo de simplemente transferir el paro fuera de las propias fronteras?). Y, sobre todo, esta autora reintroduce en el entorno económico obrero a las trade unions, que Keynes había preferido no contemplar. Según ella, el pleno empleo puede ser definido por la ausencia de un ejército de reserva industrial. Y demuestra que esto solo puede lograrse mediante un proceso inflacionista, con continuos incrementos de salarios y precios, resultando por lo tanto incompatible con el equilibrio. De nuevo a diferencia de Keynes, Joan Robinson no tiene en cuenta la «preferencia de liquidez», es decir, supone que este factor psicológico se mantiene constante. Así que los cambios en términos de necesidad de medios monetarios, con determinada tasa de interés, se explican sobre todo por los movimientos de los salarios. De lo que concluye que el banco central y los sindicatos se reparten el control del movimiento de los precios en general.

En el penúltimo capítulo, titulado «Sermón de un economista», la autora se pregunta cómo justificar la tesis tradicional según la cual la disminución de la demanda de bienes de consumo, debida a la transferencia de los ingresos de la población más pobre -que por lo tanto ya no va a gastarlos- a la más rica - que por lo tanto incrementará sus ahorros- vendría a determinar un aumento de la demanda, ya sea de trabajo, ya sea del capital necesario para producir dichos bienes. Es al obispo de Gloucester a quien viene así a criticar, por haber defendido que el mejor medio para ayudar a los parados consistía en permitir que los ricos incrementaran sus gastos mediante desgravaciones de impuestos. 


\title{
LA “TeOría general” de John Maynard Keynes ${ }^{43}$
}

\author{
MAURICE HALBWACHS
}

A las razones que siguen a continuación para volver a prestar atención a la última gran obra de Keynes habría que añadir, hoy por hoy —es decir, desde la guerra-, otra más de plena actualidad pues se trata de la que va a ser desde ahora, y durante los años venideros, la política financiera del Gobierno británico.

El economista inglés ha planteado, en efecto, en dos muy sonados artículos publicados en el Times, el problema en los siguientes términos: comienza recordando la declaración del Canciller, según la cual el Gobierno deberá absorber la mitad, o casi, de la renta nacional. Hay que tener en cuenta, por otro lado, la devaluación del potencial de producción. El Canciller ha declarado en la Cámara de los Comunes que, en semejantes condiciones, todas las capas de la comunidad británica, y no solo los ricos, deberán llevar a cabo sacrificios para financiar la guerra.

Keynes prosigue: la clase obrera inglesa está recibiendo la mayor parte de la renta nacional. Habría que ver cómo lograr que contribuya a la financiación de estos gastos, sin que esto suponga un excesivo quebranto para ella. Aunque el Canciller haya propuesto estabilizar los salarios, cabe esperar que estos aumenten rápidamente, según Keynes. Este prevé incluso un incremento del poder adquisitivo de los asalariados del orden de 500 millones de libras anuales. Por lo que, a su parecer, el Estado debería intervenir para impedir que la clase obrera, al poseer unos ingresos sensiblemente superiores a los correspondientes a hace cuatro o cinco meses, consuma más de lo que consumía, por ejemplo, durante el primer semestre del año.

¿Pero cómo hacerlo? ¿Mediante el incremento de precios? Este debería ser entonces superior al incremento de los salarios. En realidad, cada uno de estos incrementos arrastraría a su vez al otro y los incrementos salariales resultarían siempre superados por los incrementos de los precios. «No estoy sistemáticamente en contra \asegura Keynes $\bigotimes$ de los impuestos sobre el capital. Ya los preconicé tras la última guerra y recomendaré su aplicación tras esta. Pero, en el momento actual, la inflación temporal aumentaría la parte de la renta de los más ricos, y es contra esta que hay que defenderse. Lo que pretende mi plan es impedir la repetición de lo que ha pasado la última vez». El riesgo es que así la clase obrera no reciba nada a cambio de sus horas de trabajo extra y de su gran esfuerzo suplementario.

Hay por lo tanto que recurrir a otros medios: impuestos y préstamos. «En cualquier caso, los impuestos no bastan. Además, si el trabajador ve desaparecer vía impuestos una parte del excedente de sus ingresos, ¿cómo no va a preferir que se sustituya, por lo menos en parte, pagar impuestos por conceder préstamos?». «En conclusión -nos plantea Keynes-, hay que lograr que los trabajadores estén dispuestos a renunciar a la disposición inmediata de la totalidad del aumento de sus salarios, aceptando el pago diferido de una parte de dicho aumento. [...] Es preferible, para la clase obrera, ser obligada a economizar antes que resultar privada del valor real de sus ganancias, debido a una inflación temporal».

No vamos a entrar en el detalle del proyecto de Keynes, que prevé que una parte del aumento salarial sea apartada a crédito del asalariado (si bien generando intereses) en cajas de ahorros, donde quedaría bloqueada hasta el final de la guerra, cuando volvería a ser puesta a su disposición. Lo más sorprendente y digno aquí de mención es que precisamente el economista que más ha insistido en el efecto negativo del ahorro, hablando siempre con gran ironía del deber puritano de ahorrar e invertir, pretendiendo que se fomentara lo más posible la «propensión al consumo», haya

43 "La théorie général de John Maynard Keynes" se publicó en 1940 en Annales sociologiques, serie D, fascículo 4, pp. 25-41. ), Reimpresa en Maurice Halbwachs, Keynes, abstraction et expérience. Sur la Théorie génerale, París, Édtions Rue d' Ulm, pp. 81-97. De donde la reproducimos. Traducción de Eric Jalain, revisada por Luis Enrique Alonso e Ignacio Duque.. 
cambiado tan radicalmente de postura. Esto es sin duda debido a que en su gran obra se trataba de lograr el full employment en una situación económica ya muy lejana. Pero Keynes puede sostener que en el presente el «pleno empleo» está prácticamente a punto de lograrse en Gran Bretaña (aunque, a decir verdad, en estos momentos aún no se haya llegado a este punto y todavía exista una elevada proporción de parados), de manera que nos encontraríamos casi en la hipótesis que siempre había reprochado a los clásicos de haber considerado en exclusiva.

De ahí este nuevo programa, en torno al cual se ha suscitado una controversia entre los representantes más calificados del laborismo y Keynes. Parece ser que el Consejo general de las Trade Unions ha hecho saber al Canciller que antes de contraponer su plan al del Gobierno, quiere consultar a algunas personalidades prominentes, especialmente a Sir Walter Layton, Sir Arthur Salter y John Maynard Keynes. Así que, de repente, el más esotérico de los economistas ingleses viene a ser considerado una autoridad por aquellos que mejor representan las reacciones instintivas de la clase obrera de este país; su prestigio parece desbordar singularmente el círculo de su profesión. Nos limitamos a constatar este hecho, que en todo caso viene a suponer un aliciente para aquellos lectores que en principio puedan sentirse poco inclinados a interesarse por lo expuesto a continuación, en la medida en que advertirán que esta doctrina aparentemente construida en el mundo de las abstracciones puras no carece sin embargo de relación con la práctica ni con las preocupaciones del presente.

En nuestro fascículo precedente no hemos dado más que dos indicaciones muy someras sobre la última gran obra de Keynes (The General Theory of Employment, Interest and Money. London: MacMillan, 1936, XII-403 p., in-8 ${ }^{\circ}$; La teoría general del empleo, el interés y el dinero), y sobre el libro de Joan Robinson, dedicado al empleo y la teoría del interés (Annales sociologiques, D3, [1938], pp. 70, 71 y 114). Pero teníamos toda la intención de volver a ello, por todo el esfuerzo invertido en esta obra y por el prominente lugar que ha logrado y que conserva entre los economistas anglosajones. Plantea uno de esos problemas de método que ciertamente no conviene subestimar. Pues es en el terreno metodológico donde se determinan los progresos decisivos, los que deciden todo el futuro de una ciencia. Cualquier error, incluso cualquier compromiso ecléctico en este punto podría condenar a todo el conjunto de los especialistas en la materia a un estancamiento indefinido. Vale pues la pena mantener siempre la guardia bien alta y, sobre todo en los inicios, escoger cuidadosamente la ruta a seguir.

La teoría de Keynes es denominada general en aquello que la distingue de la teoría clásica, que solo se ajusta a una situación de equilibrio posible, que no se corresponde a la sociedad económica en la que vivimos. He aquí los postulados de la teoría clásica del empleo (de mano de obra): $1^{\circ} \mathrm{El}$ salario es igual al producto marginal del trabajo, es decir, al valor que se perdería si el empleo se redujera de una unidad; $2^{\circ}$ La utilidad del salario, cuando se emplea un volumen determinado de trabajo, es igual a la disutility marginal de dicha cantidad de empleo (por disutility entendemos todas las razones que pueden conducir a una persona o grupo a no ofrecer su trabajo por un salario cuya utilidad para ellos sea inferior a un mínimo), es decir, cuando el salario real de una persona empleada es justo el suficiente para propiciar el volumen de trabajo actualmente empleado. De lo que se deduce que solo existen cuatro medios para aumentar el empleo: $1^{\circ}$ Suprimir las fricciones; $2^{\circ}$ Disminuir la disutility marginal del trabajo para reducir el paro voluntario; $3^{\circ}$ Incrementar la productividad física marginal de las industrias que producen los bienes comprados con estos salarios; $4^{\circ}$ Aumentar los precios de los demás bienes, incrementando la compra de los mismos por parte de los no asalariados.

Es admitido, por lo tanto, que si la demanda de trabajo al salario nominal actual puede ser satisfecha antes de que todos los que consientan trabajar por dicho salario sean empleados, es porque existe un acuerdo público o tácito de los obreros para no trabajar por menos. Si el trabajo en su conjunto consintiera una reducción de salarios, existiría más empleo. Este paro sería pues voluntario. Pero los hechos no confirman que el paro en tiempos de depresión sea el resultado de que los trabajadores se resistan a una reducción de su salario nominal. Por lo demás, el salario real no constituye una indicación conveniente de la disutility marginal del trabajo.

Existe, no obstante, a decir de Keynes, una objeción más fundamental. La teoría tradicional pretende que las negociaciones entre empresarios y trabajadores en torno al salario nominal determina el salario real, desde el momento en que estos puedan igualar dicho salario real a la 
disutility de la cantidad de empleo ofrecida en dicho nivel de salario. Pero esto contradice la tesis clásica según la cual los precios resultan del coste de producción en términos monetarios. Si los salarios nominales cambian, los precios también deberían cambiar en la misma proporción y los salarios reales y la cantidad de empleo no cambiar. En realidad, la lucha en torno a los salarios nominales afecta sobre todo a la distribución del conjunto de los salarios reales entre los diversos grupos de trabajadores, y no al nivel general (medio) de los salarios reales, que depende de otros factores. Afortunadamente, los trabajadores no suelen luchar contra el aumento del coste de la vida, pues esto supondría un obstáculo al aumento del conjunto del empleo.

Pero definamos el otro tipo de paro, el involuntario, que la teoría clásica no cree posible. Se produce cuando, en caso de un pequeño aumento del precio de los bienes comprados por los asalariados, la oferta total de trabajadores que consiente a emplearse por el salario nominal en curso y la demanda total de dicho trabajo por semejante salario resulta mayor que el volumen de empleo existente. Esto no puede ocurrir cuando existe pleno empleo (full employment, igualdad del salario real con la desutility marginal del empleo), pero esto no es el caso en la sociedad en la que vivimos.

Pero en cualquier caso, el primer postulado no deja de ser cierto: ceteris paribus (técnica, equipamiento, etc.), el producto marginal en las industrias que producen bienes comprados por los asalariados decrece a medida que aumenta el empleo (ley de los rendimientos decrecientes).

Cuando el empleo aumenta, los ingresos reales totales también aumentan, así como -debido a la psicología comunitaria- el consumo total, aunque no tanto como los ingresos. Pero los empleadores perderían si la totalidad del aumento del empleo se consagrara a satisfacer la demanda incrementada por el consumo inmediato. Así pues, para justificar una determinada cantidad de empleo, debe existir una cantidad suficiente de inversiones corrientes que absorba la parte de la producción total que exceda lo que la comunidad ha decidido consumir cuando el empleo se halla en un nivel determinado. En caso contrario, las ganancias de los empresarios resultarían insuficientes para incitarlos a ofrecer esta cantidad de empleo. De esto se deduce que, habida cuenta de la tendencia de la comunidad a consumir, el nivel de equilibrio del empleo ఐpunto en el cual el conjunto de empresarios ya no tiene motivos ni para aumentar ni para disminuir el empleo囚 va a depender de la cantidad de inversiones. Por lo que puede producirse un equilibrio estable por debajo del full employment.

De ahí la paradoja de la pobreza en plena abundancia. Una demanda efectiva insuficiente puede detener el aumento del empleo antes de llegar al full employment, es decir, cuando el producto marginal del trabajo supera en términos de valor el punto a partir del cual el empleo deja de resultar útil. Cuanto más rica sea una comunidad, más amplio tiende a ser el intervalo entre su producción real y potencial. Pues una comunidad pobre tiende a consumir la mayor parte de su producción, por lo que bastan unas inversiones muy reducidas para asegurar el full employment, mientras que una comunidad rica deberá buscar mayores oportunidades de inversión para que la tendencia a economizar de sus miembros más adinerados resulte compatible con el empleo de sus miembros más pobres. Y lo que es peor: no solo la propensión marginal al consumo resulta más débil en una comunidad rica, sino que además, como ya existe una gran acumulación de capital, las oportunidades de futuras inversiones resultan menos atractivas, a no ser que la tasa de interés (por el préstamo de dinero o las deudas) disminuya de forma bastante rápida.

Así, el análisis de la propensión al consumo, la definición del rendimiento marginal del capital y la teoría de la tasa de interés constituyen pues las tres principales lagunas de la teoría clásica. El ahorro (saving) es una operación de doble cara: aunque, para un individuo la suma de sus ahorros carece de una influencia previsible sobre sus propios ingresos, las reacciones que provoca la cuantía de su consumo sobre los ingresos de otras personas imposibilitan que todos los individuos ahorren a la vez ciertas sumas. Resulta además igual de imposible que una comunidad ahorre menos que la suma de las inversiones corrientes.

Analicemos primero la propensión al consumo, que depende de ciertos factores objetivos: $1^{\circ}$ De un cambio en la unidad de salario: en una situación dada, los ingresos reales de una persona aumentan o disminuyen en la misma medida en que desarrolla unidades de trabajo, es decir, con la suma de sus ingresos valorada en unidades de salario; $2^{\circ}$ De un cambio en la diferencia entre ingresos e ingresos netos (puesto que el consumo depende de los ingresos netos); $3^{\circ}$ De cambios 
accidentales en el valor del capital que no se han tenido en cuenta en el cálculo de los ingresos netos; $4^{\circ}$ De cambios en la tasa de descuento (relación de canje entre bienes presentes y futuros); $5^{\circ}$ De cambios en la política fiscal.

Cuanto mayor sea la reserva financiera necesaria antes de recibir los ingresos netos, menos favorable al consumo y, consecuentemente, al empleo resultará el nivel de inversiones. Tomemos por ejemplo una casa para cuya reconstrucción se aparta cierto dinero cada año, pero sin llevar a cabo mientras tanto ningún mantenimiento. En una economía no estática, durante un periodo en el que se multiplican las inversiones en capital de larga duración, una gran parte de las nuevas inversiones puede ser absorbida por las amplias reservas financieras realizadas por empresarios, debido al equipamiento en capital existente para las reparaciones y la renovación del mismo, pues aunque se desgaste con el paso del tiempo, aún no ha llegado el momento de gastar una cantidad que se aproxime a las sumas así acumuladas; de ello resulta que los ingresos no pueden elevarse por encima de un nivel bastante bajo, correspondiente a un total escaso de nuevas inversiones. Todas estas reservas de fondos pueden acabar menguando el poder adquisitivo de los consumidores mucho antes de que se recupere la demanda relacionada con los gastos en remplazos (anticipados por estas reservas). La demanda efectiva solo aumentará así el año en que se efectúen dichos remplazos. Esto suele contribuir de forma importante a reducir los ingresos netos disponibles para el consumo (y, en consecuencia, el empleo).

En lo referente a las inversiones públicas, la población suele comprender tanto la importancia del mantenimiento y como de la construcción de carreteras y casas, dependencias municipales, instalaciones de agua, etc. Es una forma de adelantarse a posibles dificultades futuras. Pero esto resulta aún más evidente en el caso de las inversiones privadas; el capital no es una entidad que se agote en sí misma, independientemente del consumo.

En cuanto a los factores subjetivos, se trata de los motivos que impiden a los individuos gastar sus ingresos: reservas frente a contingencias, conseguir una renta más elevada en el futuro, disfrutar de mayor consideración, encarar gastos progresivamente crecientes, disponer de un margen de maniobra, dejar una herencia o motivos como la simple avaricia.

Para una persona que ha estado largo tiempo en el paro, la disutility marginal puede resultar muy inferior a la utilidad marginal del producto. Se puede así constatar hasta qué punto muchos gastos financiados con endeudamiento pueden enriquecer a la comunidad; desde la construcción de pirámides, hasta los terremotos o las guerras pueden de esta manera incrementar la riqueza. El sentido común no se equivoca y parece aceptable que los seguros de paro sean financiados mediante endeudamiento en vez de que sea el Estado quien financie mejoras por debajo de las tasas corrientes de interés. La mejor solución parece ser la explotación de las minas de oro, que nada añaden a la riqueza del mundo e implican disutility del trabajo. Debemos soportar las miserias del paro porque aplicamos a la conducta del Estado las máximas más adecuadas para enriquecer a un individuo, permitiéndole acumular títulos que no tiene intención de utilizar en ningún momento concreto.

Con la incitación a la inversión vamos a abordar la cuestión del interés. La tasa de inversión, nos dice Keynes, se incrementa hasta el punto en el que la eficacia marginal del capital iguala a la tasa de interés en el mercado.

Efectivamente, en este tema nos basamos sobre todo en el presente, en el estado de confianza. Se trata principalmente de todo aquello que puede influir en la psicología de masas. Se puede anticipar una base de evaluación para algunos meses, pero no evaluar el rendimiento en un plazo futuro de varios años. Es como en esos concursos de los periódicos donde los participantes deben elegir las seis fotografías más atractivas entre cientos de ellas, de manera que señalan no tanto las fotografías que cada uno halla más atractivas como las que piensan que van a resultar más atractivas para toda la masa de lectores (haciendo cada uno, de hecho, el mismo cálculo). ¿Pero es este siempre el medio de lograr el mayor provecho para todos?

Y una vez que se decide ahorrar, ¿cuál sería el grado de preferencia de liquidez (la cuantía de lo que se quiere guardar en forma de moneda)? El error de las teorías es que intentan derivar la tasa de interés de la propensión al consumo (o a no consumir) de la economía como tal. Pero si una persona decide atesorar en efectivo, no existe interés. Para tenerlo, debe renunciar a la liquidez durante cierto tiempo. El interés es por lo tanto el precio que equilibra el deseo de guardar 
el dinero en efectivo (cash) y la cantidad disponible de cash. Si la tasa de interés es muy baja, la cantidad de dinero en efectivo que la población quiere conservar puede llegar a superar a su oferta (de cash), por lo que puede darse un excedente de dinero en efectivo que nadie quiere guardar.

La cantidad de moneda (M) constituye pues el segundo factor que se combina con la preferencia de liquidez (L) para determinar la tasa de interés (r); de ahí la siguiente fórmula: $\mathrm{M}=\mathrm{L}(\mathrm{r})$.

Pero cabe distinguir el uso de efectivo para las transacciones corrientes de su uso como reserva de riqueza. ¿A qué se debe la preferencia de liquidez? Para que se dé, se requiere una incertidumbre sobre el futuro de las tasas de interés. Además, cada persona puede estimar de manera diferente las perspectivas a este respecto.

Aquel individuo que piense que más adelante la tasa de interés (para depósitos a largo plazo) será más elevada que en el mercado actual tiene una buena razón para guardar el dinero en efectivo. Intervienen aquí tres motivaciones: de transacción, de precaución y de especulación. En ausencia de un mercado organizado, tenderá a imperar la motivación de precaución. Pues es el mercado organizado el que pone en marcha la motivación especulativa. Aunque sea de esperar que un aumento en la cantidad de moneda reduzca la tasa de interés, esto puede no ocurrir si la preferencia de liquidez de la población aumenta más que dicha cantidad. El interés no constituye pues una recompensa al not spending ['no gastar'], sino al not hoarding ['no atesorar'].

Los clásicos admiten que, con un nivel de ingresos dado, la tasa corriente de interés debe alcanzar el punto donde la curva de demanda de capital cruce la curva de las cantidades ahorradas (procedentes de estos ingresos). Pero pasan por alto la influencia de los cambios en el nivel de los ingresos. Estas funciones nos podrían indicar dicho nivel si conociéramos (por otras fuentes) la tasa de interés. En realidad, ahorro e inversión son elementos determinados por el sistema, no elementos determinantes del mismo, que son la propensión al consumo, la escala de la eficacia marginal del capital y la tasa de interés. Los ingresos dependen de las inversiones y cambian cuando estas cambian, de manera que los cambios en los ahorros igualan a los cambios en las inversiones. Esta cuestión es de una importancia capital, pues los economistas, desde un punto de vista práctico, consideran invariablemente que una disminución de los gastos tiende a bajar la tasa de interés, mientras que un aumento de las inversiones tiende a elevarlo. Pero si estas dos magnitudes no determinan la tasa de interés, sino el volumen conjunto del empleo, entonces nuestra perspectiva sobre el mecanismo del sistema económico se ve profundamente transformada. Toda disminución de la tendencia a gastar va a ser juzgada de manera muy diferente si en lugar de ver en ella un factor que incrementa las inversiones, vemos un factor de reduce el empleo.

Retomando ahora la teoría del empleo (de mano de obra) en su conjunto, Keynes observa que una característica de nuestro sistema económico (basándonos en la experiencia, aunque no derive de una necesidad lógica) consiste en que, si bien parece sujeto a fuertes fluctuaciones en lo referente a la producción y empleo, tampoco resulta excesivamente inestable. Parece de hecho capaz de permanecer, durante periodos muy prolongados, en una situación crónica de baja actividad. Es más, el pleno empleo, o prácticamente pleno, es raro y de corta duración. En cuanto a las fluctuaciones, pueden iniciarse bruscamente, pero parecen perder fuerza por sí mismas antes de llegar a extremos (de ahí la teoría de los ciclos); lo mismo ocurre con los precios. Tanto el entorno como las tendencias psicológicas del mundo moderno también se corresponden a estos resultados. ¿Pero cuáles son estas condiciones hipotéticas?

$1^{a}$ La propensión marginal al consumo es tal que, cuando la producción de una determinada comunidad aumenta (o disminuye) porque se emplea más (o menos) mano de obra al equipamiento en capital, el multiplicador de las inversiones (número por el que hay que multiplicar el incremento de las inversiones para obtener un incremento de la producción) es mayor que la unidad, pero no mucho mayor. La propensión al consumo aumenta pues moderadamente.

$2^{a}$ Los cambios moderados en la previsión del rendimiento del capital no van asociados a grandes cambios en las tasas de inversión.

$3^{\text {a }}$ Cuando se produce un cambio en el empleo (de mano de obra), los salarios nominales tienden a cambiar más o menos proporcionalmente en la misma dirección.

$4^{\text {a }}$ Una tasa de interés más (o menos) elevada que la establecida afecta desfavorablemente (o favorablemente) a la eficacia marginal del capital, si dicha elevación es 
sostenida en el tiempo (en términos de años).

Pero son estos hechos empíricos, no principios necesarios e inamovibles.

La teoría clásica plantea que una reducción de los salarios nominales estimularía la demanda al disminuir los precios de los productos acabados, y por consiguiente aumentaría la producción y el empleo hasta el punto de que la mengua salarial aceptada resultaría compensada por la bajada del rendimiento marginal a medida que la producción (con un equipamiento dado) se incrementara. Pero Keynes considera que la política más conveniente consistiría en mantener estable el nivel general de salarios nominales, de lo que se derivaría una gran estabilidad en los niveles de precios. Esto a corto plazo. A largo plazo, lo mejor sería permitir que los salarios fueran aumentando lentamente, mientras se mantienen los precios estables, antes que dejar caer los precios lentamente, debido a la aplicación de los progresos técnicos y a la estabilización salarial. Esta sería la mejor manera de acercarse al full employment. David Ricardo pensaba que se podía pasar por alto «esta función de la demanda total» (o sea, el poder adquisitivo, como se dice hoy en día). Ricardo conquistó Inglaterra tal como la Santa Inquisición se había apoderado totalmente de España. Logró una gran autoridad gracias a que pudo explicar numerosas injusticias sociales y crueldades aparentes como accidentes inevitables en la marcha del progreso, y a que sostuvo que los intentos de cambiar todas estas cosas podían, a fin de cuentas, acabar haciendo más mal que bien. Así como gracias a que justificó las libres actividades del capitalismo individual.» Pero estos planteamientos no permiten previsiones científicas.

Veamos a continuación las conclusiones más generales e incluso, como el propio Keynes dice, la filosofía social que se deriva de todas estas deducciones.

Parecería que, en las condiciones imperantes hasta épocas recientes (inversiones sin planificación, control ni conocimientos), no existiría otro medio para aumentar el empleo que el incremento del consumo. Pero, en la práctica, un incremento de las inversiones conlleva numerosas ventajas sociales.

Solo en las condiciones de full employment, una escasa propensión al consumo puede obstaculizar el incremento del capital. Pero una redistribución de los ingresos que favorezca el consumo puede resultarle beneficiosa. Un aumento en la propensión al consumo puede servir para aumentar al mismo tiempo la tendencia a la inversión.

La magnitud de los ahorros viene determinada por la escala de las inversiones y esta, a su vez, por una baja tasa de interés. Dicha tasa puede reducirse apreciablemente si es posible mantener unas condiciones más o menos continuas de full employment.

Cabe además destacar que el propietario del capital se aprovecha de su escasez. Pero dicha escasez no es necesaria. El aspecto rentista del capitalismo (functionless investor) corresponde a una fase transitoria: esta forma de capitalismo desparecerá cuando haya cumplido su papel.

En cualquier caso, puede ocurrir que la propensión al consumo resulte tan fortalecida por el efecto de una bajada del interés que se pueda alcanzar el full employment con tasas de acumulación apenas mayores que las actuales.

El Estado, finalmente, debería ejercer una influencia rectora en la propensión al consumo, en parte mediante sus planes fiscales, en parte mediante la fijación de la tasa de interés, o bien por otros medios.

Sobre el temperamento intelectual de Keynes y sobre los rasgos esenciales de su obra económica, nos remitimos al informe aportado por Simiand en «Sur une théorie finaliste et britannique de la monnaie», Annales sociologiques, D1, pp. 158-172, dedicado a su libro A Treatise on Money, 2 vol., 1930.

Pero en cualquier caso, no deja de ser impactante hasta qué punto los conceptos empleados por Keynes en sus análisis nos parecen alejados de la realidad; no contienen, por sí mismos, nada real que podamos captar y observar en ningún sitio. Esto se hace menos evidente en las cuestiones monetarias, porque se trata en sí mismo de un mundo extraño a lo común, caracterizado por técnicas complicadas y abstractas que parecen tolerar la intervención de todo un juego de conceptos esotéricos (si bien, incluso en este ámbito cabría aplicar la misma objeción). Pero en este libro pasa a un primer plano un problema tan vivo y presente como el paro, relacionado con hechos muy cercanos a cualquiera de nosotros, como el salario, el coste de la vida, las actitudes de los patronos y de los obreros. ¿Pues cómo no sentirse desconcertado ante la idea de tener que 
partir de conceptos tales como el rendimiento marginal del trabajo o la disutility marginal de una unidad de empleo, que han sido elaborados por la economía política más abstracta y que aún resultan muy controvertidos? ¿Acaso existen, de alguna manera, en la consciencia individual o colectiva de los obreros? ¿Responden a una realidad efectivamente observable, fuera del ámbito de las abstracciones? Keynes pone en el mismo plano el salario nominal y el salario real; pero se ha demostrado que el salario real, muy a pesar de su nombre, tiene poco que ver con la realidad. ¿Hay acaso otro medio que no sea la observación para saber si existe un salario mínimo nominal por debajo del cual, sean cuales sean las circunstancias, los obreros nunca aceptarían trabajar?, ¿o si, en ciertas circunstancias, consentirían trabajar por debajo del salario medio y en qué medida? ¿Acaso no depende todo esto del país, del entorno, de las costumbres, del tipo de vida, así como de la edad y de la profesión? Keynes nunca llega a plantearse estas preguntas. Sin embargo, todo su análisis avanza como si hubieran quedado resueltas, ora porque se refiere a un estado de cosas que no es sin embargo válido fuera de las condiciones de tiempo y lugar en las que es observado, ora porque se contenta con verdades evidentes como que hay paro involuntario cuando los obreros que quieren trabajar no encuentran empleo.

Podríamos hacer las mismas observaciones con respecto a la propensión al consumo, una de las nuevas variables introducidas por Keynes en su teoría. ¿Acaso basta con enumerar los factores objetivos y subjetivos de los que depende? Enumeración bastante banal, que aunque sirve para repasar posibilidades, no nos enseña nada sobre la intensidad de dicha propensión, más allá de que aumenta con los ingresos totales, pero más lentamente. Y sobre los ingresos totales, mucho queda por decir, pues aparte de los ingresos derivados de actividades productivas, están los que proceden de otras prestaciones, de la propiedad de inmuebles, de títulos, de ahorros anteriores y un largo etcétera nada desdeñable. Y esa propensión al consumo, ¿cómo se determina? No se establecen distinciones en función de las clases, de los grupos profesionales, ni de los objetos de consumo. En realidad, la propensity to consume solo interesa a Keynes en la medida en que se opone al ahorro. Todo este enorme esfuerzo analítico al fin y al cabo se basa en conceptos muy generales y muy indefinidos a los que se aplica. Es necesario que los ingresos totales se repartan entre el consumo y el ahorro, pues la producción no podría incrementarse sin no se invirtiera una parte de los mismos. Esto no es más que un truismo. Junto con esto, Keynes plantea la idea de que unas reservas financieras excesivas reducen los ingresos netos disponibles para el consumo y, por consiguiente, para el empleo. En este punto cabrían numerosos matices, en función de los países y de su grado de desarrollo. Pero volveremos a ello.

Limitémonos de momento a las siguientes fórmulas: si llamamos $\mathrm{Y}$ a los ingresos, $\mathrm{C}$ al consumo e I a las inversiones, $\mathrm{dC}_{\mathrm{w}} / \mathrm{dY}_{\mathrm{w}}$ constituye la propensión marginal al consumo. Magnitud de gran importancia, según Keynes, pues nos permite conocer cómo se va a repartir el próximo aumento de la producción entre consumo e inversión. $\Delta \mathrm{Y}_{\mathrm{w}}=\Delta \mathrm{C}_{\mathrm{w}}+\Delta \mathrm{I}_{\mathrm{w}} \cdot \Delta \mathrm{Y}_{\mathrm{w}}=k \cdot \Delta \mathrm{I}_{\mathrm{w}}$, donde 1 - $1 / k$ es la propensión marginal al consumo y $k$ es el multiplicador de inversión. El problema es que para conocer $k$ hay que extraerlo de la propensión marginal al consumo y... ¿ idónde y cómo observarla y calcularla?

Lo que nos conduce al análisis del ahorro en términos de inversión y atesoramiento (o preferencia de liquidez). Aquí de nuevo Keynes reduce sus motivaciones a la siguiente enumeración: de transacción, de precaución y de especulación. ¿Pero no existen acaso otras motivaciones, es decir, la preferencia por el dinero en efectivo no puede explicarse por otras razones, como aquellas mismas a las que acude para explicar el ahorro? Pues en ciertos casos no es más que una de las formas que adopta el ahorro. En cualquier caso, no hay nada aquí que no quepa en una observación empírica elemental; no deja de tratarse de posibilidades. En cuanto a la intensidad absoluta o relativa de estas motivaciones, ¿cómo podríamos medirla? Keynes añade: ciertamente, para que se produzca la preferencia de liquidez tiene que darse una incertidumbre sobre el futuro de la tasa de interés. Asegura (véase nuestro informe precedente sobre esta parte de su libro, en Annales sociologiques, D, fasc. 3) que el volumen de las inversiones se ajusta al punto en el que la eficacia marginal del capital coincide exactamente con el nivel de la tasa de interés corriente. Finalmente, según él la tasa de interés es (junto con la propensión al consumo y la eficacia marginal del capital) una variable independiente, uno de los elementos determinantes del sistema (y no uno de los elementos determinados por este), constituyendo por ejemplo una de 
las principales influencias sobre la preferencia por la liquidez. Todo esto tal vez pueda ser cierto en una sociedad económica muy evolucionada, cuyos miembros se preocupen ante todo en hallar el destino más lucrativo para la parte de sus ingresos que no consumen, en forma de préstamos a corto o largo plazo, tanto en la industria como en el comercio, o bien en depósitos a la vista, o manteniéndola en reserva en previsión de eventuales especulaciones, etc. Pero esto solo constituye una situación particular, que el autor ha podido observar, cuya extensión y desarrollo ha podido constatar en su entorno, pero en un lugar y periodo limitados, sin que podamos saber si se trata de un estado o fenómeno normal o excepcional, no resultando por lo tanto muy propio para fundar una teoría general.

Pero tras todas estas objeciones y reservas, reconozcamos que Keynes ha tenido el mérito de construir una teoría del empleo (de mano de obra) tanto analítica como sintética que, aunque en la línea de los clásicos, escapa a las limitaciones de las construcciones de estos. Él mismo era consciente de ello, demostrando cómo dichas teorías se aplicaban en un estado de equilibrio sin relación alguna con las condiciones económicas que conocemos. ¿Pero cabría por ello pensar, no obstante, que mediante un simple esfuerzo de reflexión crítica ha podido detectar las lagunas de sus concepciones, los errores de sus razonamientos, y que los ha superado con mayores dosis de lógica, porque ha sabido aplicar mejor el método conceptual y dialéctico que comparte con los clásicos?

Pues no. En realidad, Keynes vivía en una época donde las condiciones económicas eran muy otras, y especialmente donde la cuestión del paro y del empleo se hallaba en primer plano. Así que se vio obligado a forjar nuevos conceptos y a plantear nuevas hipótesis, lo que explica la apariencia tan moderna de su teoría, pues aborda las cuestiones de mayor actualidad. A comienzos del siglo XIX, la industria necesitaba una cantidad creciente de obreros, a pesar de los periodos de parón y estancamiento. Disponía además de una mano de obra cuyas exigencias materiales se reducían a lo indispensable. Si definimos el full employment como el empleo tal como se da cuando lo que se puede comprar con el salario satisface las exigencias de todos los que se presentan a trabajar (es efectivamente el sentido de la ecuación: utilidad del salario = disutility marginal del empleo), en aquella época se estaba a menudo más cerca de esta situación que hoy en día, precisamente porque los obreros se contentaban con mucho menos. Teóricamente, los economistas podían haber creído que, salvo en periodos excepcionales de crisis, esta era la situación normal, pues no veían ninguna restricción (salvo las dictadas por las mismas condiciones biológicas de la propia vida) a la hora de imponer límites a las demandas ya de por sí muy tímidas de la clase obrera. Hoy en día, la situación es muy otra: una industria limitada, a veces en regresión, ha de enfrentarse a una población obrera excedentaria, con exigencias crecientes y, en cierta medida, irreductibles. Así que el full employment parece un ideal que se aleja cada vez más. Hacía falta pues una nueva teoría para analizar una situación nueva. El método sigue siendo conceptual, pero se aplica de forma diferente pues el teórico - sea o no consciente de ello- debe responder a las cuestiones que la realidad le plantea. Y tal vez sea la señal de que, hoy como ayer, el método no puede ser plenamente conceptual más que en apariencia. Pero lo que es más grave es que el teórico sea totalmente incapaz de identificar la parte de la realidad que se introduce subrepticiamente en sus concepciones. Además, la realidad no puede compartimentarse. Hay que considerarla en su totalidad o no considerarla. 